\title{
Assessment of corroded prestressed and post- tensioned concrete structures: a review
}

\author{
Eline Vereecken $^{\mathrm{a}, \mathrm{b}, *}$, Wouter Botte ${ }^{\mathrm{a}}$, Geert Lombaert $^{\mathrm{b}}$, Robby Caspeele $^{\mathrm{a}}$ \\ ${ }^{a}$ Department of Structural Engineering and Building Materials, Ghent University, Ghent, Belgium \\ ${ }^{\mathrm{b}}$ Department of civil engineering, KU Leuven, Leuven, Belgium \\ *Corresponding author at Technologiepark-Zwijnaarde 60,9052 Ghent, Belgium; eivereec.vereecken@ugent.be
}

\begin{abstract}
Prestressed structures are commonly used all over the world. They might be subjected to degradation, such as corrosion of the prestressing steel. This can influence the resistance of these structures and induce early failure. Hence, prediction of the corrosion level is important in the assessment of existing prestressed structures. For this purpose, the corrosion process and the accompanying influences on the structure should be modelled. For reinforced concrete structures, a lot of research and guidelines are available to model the corrosion process. Nevertheless, this corrosion process might differ for prestressed structures, due to the different structural composition, the different geometry of the strands or tendons compared to reinforcement bars, the presence of the prestress, etc. Moreover, for post-tensioned structures, initiation and propagation of corrosion are even more different from corrosion in reinforced concrete structures, due to the location of the steel in ducts and the lack of direct contact with the surrounding concrete. In this paper, a state-of-the-art on the assessment of prestressed and post-tensioned structures subjected to corrosion is given based on a literature review.

Different models for the corrosion process and their influence on the structure are discussed. Comparison is made between reinforced, prestressed and post-tensioned structures. Furthermore, some assessment procedures are indicated and relevant topics for further research are given.
\end{abstract}

Keywords: prestress, post-tension, corrosion, assessment of existing structures

\section{INTRODUCTION}

Prestressed concrete structures are commonly used all over the world. In many countries, these structures are reaching the end of their design service life. Hence, questions arise on the remaining strength of these structures, especially since most of them are subjected to degradation. Inspections are performed to assess the strength of the structure, its remaining prestress, etc. However, there are no clear guidelines on the assessment of the deterioration state and the corresponding strength of these existing structures.

Reinforcement corrosion is one of the most important degradation phenomena in reinforced and prestressed concrete (PC) structures. Over the past years, a lot of research is performed on the corrosion process in reinforced concrete (RC) structures and the influence on their resistance. In prestressed structures, the effects of corrosion are also very important and can have even more influence on the structural behaviour. However, research on this topic is limited, especially when considering the assessment of existing prestressed concrete structures. In addition, studies regarding the structural response of post-tensioned structures subjected to corrosion are rather limited. For example, Podroužek, Strauss \& Bergmeister (2014) model the degradation due to corrosion by applying a reduction of prestressing tendons to critical elements in a finite element model, without modelling the actual corrosion process. Nevertheless, corrosion is a major durability concern since it might result in rupture of strands and might lead to a reduction of strength and serviceability up to an unacceptable level (Dias-da-Costa, Neves, Gomes, Hadigheh, \& Fernandes, 2019). As such, the structure might fail at an early stage due to the occurrence of brittle fracture (Page \& Page, 2007). Hence, accurate knowledge of the corrosion state and corresponding effective prestressing force is an important factor in the assessment of the structural health and corresponding performance of a prestressed concrete bridge (Osborn, Barr, Petty, Halling, \& Brackus, 2012).

The importance of studying corrosion of prestressed structures is also shown by the study of Papé \& Melchers (2011). Here, 45-year-old post-tensioned bridge girders were tested after a bridge was taken out of service. Whereas corrosion of the non-prestressed reinforcement was according to the expectations, some of the prestressing strands were severely corroded, with cross-section losses between $75 \%$ and $100 \%$. Nevertheless, little evidence of this corrosion could visually be observed since no rust stains were formed. Even in an apparently sound beam, severe localised corrosion of the prestressing strands was observed after demolition. Moreover, if rust stains were observed, they originated from corrosion of the non-prestressed reinforcement. Also in (Moravcik, Bujnakova, \& Bahleda, 2020) a precast prestressed bridge from the early 1950's was tested. Here the failure of the

Postprint submitted to Structural Concrete

Published version: Vereecken, E., Botte, W., Lombaert, G., \& Caspeele, R. (2021). Assessment of corroded prestressed and post-tensioned concrete structures: a review. Structural Concrete http://doi.org/10.1002/suco.202100050 
superstructure of the bridge was mainly ascribed to corrosion of the prestressing wires at the anchors, since these were installed without grouting and no proper maintenance was applied. As such, corrosion contributed to the loss of prestress and hence a reduced resistance of the bridge superstructure.

In this review, a summary will be given of the literature on corrosion modelling and assessment of prestressed concrete structures. Firstly, the most important differences between reinforcement corrosion and corrosion of prestressing strands are summarized. Secondly, different models for prestress corrosion and the influence on steel and concrete properties and strength are described. Thirdly, the current state of the art in relation to the assessment of post-tensioned structures subjected to corrosion is discussed. Finally, a summary is given of possible ways to assess the remaining strength of prestressed concrete structures.

\section{PRESTRESS CORROSION VS. REINFORCEMENT CORROSION}

In concrete structures, there are two important corrosion processes: carbonation-induced corrosion and chloride induced corrosion. Whereas the first induces a more global reduction in steel area, chloride-induced corrosion is often accompanied by the formation of local pits. At these pits, there is a much stronger steel material loss. It is the latter corrosion process that will be most important when considering prestressing strands, since these pits might induce strand failure more rapidly than general (uniform) corrosion, due to the presence of the prestress. The presence of this prestress is also the most important difference between reinforcement bars and prestressing strands. Due to the high prestress on stranded wires, the pitting corrosion process may be accelerated (Vu, Castel, \& François, 2009) and brittle rupture might occur earlier than expected. Vu, Castel, and François (2009) found that stress corrosion cracking would induce brittle failure of the wire when pitting corrosion has led to a $20 \%$ reduction in steel cross-section in a steel wire loaded up to $80 \%$ of its elastic limit. When the wires fail due to stress corrosion, local damage can arise in the part of the structure closest to the broken wire, with cracking in the concrete and increasing strains in the non-prestressed reinforcement (Coronelli, Castel, Vu, \& François, 2009). The higher stress levels in the wires can also lead to up to more than $15 \%$ more mass loss due to corrosion when compared to unstressed wires. On the other hand, the stress level does not influence the composition of corrosion products in the pits ( $\mathrm{Vu}$ et al., 2009). Due to the high stress levels in the prestressing steel, there will also be a coupling between conventional (pitting) corrosion and steel micro-cracking, called stress corrosion (Coronelli et al., 2009). Rupture of the prestressing strands was also observed by Naito, Sause, Hodgson, Pessiki \& Desai (2006), who investigated the corrosion of prestressing strands in prestressed concrete box girders. For this purpose, PC box beams from a 46-year-old bridge were investigated. They observed pit depths greater than $20 \%$ of the wire section area.

Besides the presence of the prestress, prestressing strands generally have a much thicker concrete cover compared to reinforcement bars, leading to a more severe corrosion degree of the latter under the same exposure conditions (Guo, Frangopol, Han, \& Chen, 2011). Chloride ions take a longer time to reach the surface of the tendons or strands and hence to induce severe corrosion. Moreover, the cracking mechanism of concrete around prestressed strands might differ from that around reinforcement bars due to the difference in shape of cross-section of the strands and bars (L. Wang, Dai, Bian, Ma, \& Zhang, 2019). Another important difference is that pitting corrosion of prestressing strands or tendons can form on each single wire. Hence, the failure of any wire will cause the increased load of other wires in the group due to stress redistribution. Moreover, according to (Guo, Chen, Liu, \& Han, 2016), these pits propagate slower in prestressing steel than in reinforcing bars due to the high quality of the steel (higher quality of the passive film) and the more strict manufacturing process. The pit depth of unstressed wires is about $30 \%$ of the one of reinforcing bars under the same circumstances (F. Li, Yuan, \& Li, 2011). However, due to stress corrosion cracking, the mass loss of a prestressing strand can become 1.3 times as large as the one from a reinforcing bar. Li et al. (2011) observed higher corrosion rates for higher levels of prestressing and a corrosion rate decreasing over time, more rapidly in the initiation stage and slower afterwards.

Not only the differences between reinforcement bars and prestressing strands are of importance, but also their interaction. As found by Guo, Frangopol, et al. (2011), loss in the non-prestressed reinforcement bars affects the structural integrity too by influencing the stress levels of the prestressing tendons. Hence, it is necessary to account for the non-prestressed reinforcements and their loss in cross-sectional area when performing reliability assessments.

The most important differences between reinforcement bars and prestressing strands are summarized in Table 1. 
Table 1 Main differences between corrosion of reinforcement bars and prestressing strands

\begin{tabular}{c|c}
\hline Reinforcement bars & Prestressing strands \\
No prestress applied & $\begin{array}{c}\text { Prestress which can result in stress corrosion } \\
\text { cracking }\end{array}$ \\
\hline $\begin{array}{c}\text { Smaller concrete cover } \rightarrow \text { More severe corrosion due } \\
\text { to smaller initiation period }\end{array}$ & $\begin{array}{c}\text { Thicker concrete cover } \rightarrow \text { Usually larger time for } \\
\text { corrosive agents to reach the strands }\end{array}$ \\
\hline Pitting on the circumference of the bars & $\begin{array}{c}\text { Pitting on individual wires } \rightarrow \text { Failure of single wires } \\
\rightarrow \text { Stress redistribution over non-failed wires }\end{array}$ \\
\hline Faster propagation of corrosion & $\begin{array}{c}\text { Slower propagation of corrosion due to higher steel } \\
\text { quality }\end{array}$
\end{tabular}

\section{MODELLING DEGRADATION DUE TO PRESTRESS CORROSION}

Corrosion of prestressing steel affects the prestressed structure in different ways. First, a reduction in steel cross section occurs due to reinforcement corrosion, which can be accompanied by wire or strand failure. Second, there is an influence on the mechanical properties of the steel, most importantly on the ultimate strain. Besides the influences on the steel, there might also be a reduction in bond between steel and concrete and cracking of the surrounding concrete can occur due to the expansive properties of rust. For all these influences of corrosion on the prestressed structures, analytical and/or empirical models exist. These can be incorporated in a finite element analysis to have a representative model of the prestressed structure, accounting for prestress corrosion. All these aspects will be covered in the sections below.

\subsection{Reduction in steel area}

\subsubsection{Chloride-induced corrosion}

Corrosion occurs in two phases: (1) an initiation period for the corrosive agents to reach the steel surface and depassivate it, and (2) a propagation phase where the steel area is reduced due to corrosion and often rust is formed. The initiation period $T_{\mathrm{i}}$ for chloride-induced corrosion is often modelled according to equation (1) and depends on the concrete cover $c$, the diffusion coefficient $D$ of the concrete (or other permeable materials surrounding the steel such as grout), the critical chloride concentration $C_{c r}$ and the surface chloride concentration $C_{s}$. The function $e r f^{1}$ refers to the inverse error function.

$$
T_{i}=\frac{1}{4 D} \frac{c^{2}}{\left(e r f^{-1}\left(1-\frac{C_{c r}}{C_{s}}\right)\right)^{2}}
$$

The initiation period is also modelled as such for prestressed structures by (Nguyen, Jeong, Han, \& Kong, 2013; Tu, Dong, \& Fang, 2019), amongst others.

For the reduction of the steel cross section in the propagation phase, different models exist. These models distinguish between uniform and pitting corrosion. For prestressed elements, the latter is the most important. For pitting corrosion, the area of a corroded bar at time $t$ is given by equation (2) according to Val \& Melchers (1997).

$$
A(t)=\left\{\begin{array}{cc}
\frac{\pi D_{0}^{2}}{4}-A_{1}-A_{2}, & p(t) \leq \frac{\sqrt{2}}{2} D_{0} \\
A_{1}-A_{2} & \frac{\sqrt{2}}{2} D_{0} \leq p(t) \leq D_{0} \\
0 & p(t)>D_{0}
\end{array} \text { with } p(t)=0.0116\left(t-T_{i}\right) i_{c o r r} R\right.
$$

Here, $R$ [-] is the penetration ratio between maximum and average penetration (ranging from 4 to 8 for reinforcement steel embedded in concrete according to González, Andrade, Alonso \& Feliu (1995)), $i_{\text {corr }}$ the corrosion rate in $\mu \mathrm{A} / \mathrm{cm}^{2}$ and $T_{i}$ [years] the initiation period.

The other parameters in equation (2) are given as follows (Val \& Melchers, 1997), with $D_{0}$ the initial reinforcement diameter: 


$$
\begin{gathered}
A_{1}=\frac{1}{2}\left[\theta_{1}\left(\frac{D_{0}}{2}\right)^{2}-a\left|\frac{D_{0}}{2}-\frac{p(t)^{2}}{D_{0}}\right|\right] ; A_{2}=\frac{1}{2}\left[\theta_{2} p(t)^{2}-a \frac{p(t)^{2}}{D_{0}}\right] \\
a=2 p(t) \sqrt{1-\left(\frac{p(t)}{D_{0}}\right)^{2}} \\
\theta_{1}=2 \arcsin \left(\frac{a}{D_{0}}\right) ; \theta_{2}=2 \arcsin \left(\frac{a}{2 p(t)}\right)
\end{gathered}
$$

Guo, Sause, Frangopol \& Li (2011) apply a truncated normal distribution (truncated at 1) for the penetration ratio $R$, with a mean value of 3 and a coefficient of variation (COV) of 0.33 , which is based on the assumption that the 95\% percentile corresponds to a penetration ratio $R=4$ (Stewart \& Rosowsky, 1998). These values have been derived for conventional reinforcement steel. The penetration ratio $R$ could also be modelled by a Gumbel distribution. A model for the maximum pit depth, over a standard length $L_{0}$ of a rebar, is given by Stewart (2009). Here, the maximum pit depth over a given length $L_{u}$ is expressed by means of the Gumbel parameters $\mu$ and $\alpha$ as given by equation (6).

$$
\mu=5.56+\frac{1}{1.16} \ln \left(\frac{L_{u}}{L_{0}}\right) \text { and } \alpha=1.16
$$

In this equation, the values 5.56 and 1.16 are the Gumbel parameters obtained from corrosion tests on a rebar of diameter $16 \mathrm{~mm}$ with standard length $L_{0}=100 \mathrm{~mm}$. The maximum pit depth should be estimated over the whole length of the reinforcements. The values 5.56 and 1.16 might change depending on the diameter of the bar, for example for a diameter of $10 \mathrm{~mm}$ they are respectively equal to 5.08 and 1.02 and for a diameter of $27 \mathrm{~mm}$ they equal 6.55 and 1.07 (Stewart, 2009). Nevertheless, for prestressing wires, much smaller diameters are often used. For these smaller diameters, no values for the parameters of the Gumbel distribution are found in literature.

Darmawan \& Stewart (2007) also developed a model for the pit depth $p(t)$, further denoted as $a$. They applied a Gumbel distribution for the maximum pit depth based on the assumptions that the wire is exposed to a uniform corrosion rate along its length. In addition, the number of pits formed and the length of the pits are assumed constant in time after an initial period of corrosion. Only the pit depth grows in time. Finally, the model also assumes that at any location of the wire only one pit can form. The Gumbel distribution for the maximum pit depth $a$ as a function of time $t$ is given by equation (7).

$$
f_{a}\left(t, i_{c o r r}, L\right)=\frac{\alpha}{\lambda^{0.54}} \exp \left(-\alpha\left(\frac{a}{\lambda^{0.54}}-\mu\right)\right) \exp \left(-\exp \left(-\alpha\left(\frac{a}{\lambda^{0.54}}-\mu\right)\right)\right) \text { if } t>T_{i}
$$

The parameters $\lambda, \mu$ and $\alpha$ are given by equations (8) to (11).

$$
\begin{gathered}
\lambda=\frac{\left[D_{0}^{2}-\left(D_{0}-0.0232 i_{\text {corr }}(1)\left\{1+\frac{\kappa}{\theta+1}\left[\left(t-T_{i}\right)^{\theta+1}-1\right]\right\}\right)^{2}\right]}{\left[D_{0}^{2}-\left(D_{0}-0.0232 i_{\text {corr }}(1)\left\{1+\frac{\kappa}{\theta+1}\left[T_{0}^{\theta+1}-1\right]\right\}\right)^{2}\right]} \\
T_{0}=\exp \left(\frac{1}{\theta+1} \ln \left(\frac{(\theta+1)\left(i_{\text {corr } \exp } T_{0-\exp }\right)+(\kappa-\theta-1)\left(i_{\text {corr }}(1)\right)}{\kappa i_{\text {corr }}(1)}\right)\right) \\
\mu=\mu_{0-\exp }+\frac{1}{\alpha_{0-\exp }} \ln \left(\frac{L}{L_{0-\exp }}\right) \text { and } \alpha=\alpha_{0-\exp } \\
i_{\text {corr }}\left(t-T_{i}\right)=i_{\text {corr }}(1) \cdot \kappa\left(t-T_{i}\right)^{\theta} \text { if } t-T_{i} \geq 1 \text { year }
\end{gathered}
$$

Here, $D_{0}[\mathrm{~mm}]$ is the initial diameter of the wire, $i_{c o r r}(1)\left[\mu \mathrm{A} / \mathrm{cm}^{2}\right]$ is the corrosion rate at the start of corrosion propagation, $T_{i}$ [years] the initiation period and $L[\mathrm{~mm}]$ is the wire length. $\kappa$ and $\theta$ are empirical factors. $\kappa$ is equal to 0.85 if the corrosion rate reduces with time and 1 if the corrosion rate is time-invariant. Accordingly, $\theta$ equals -0.29 and 0 respectively. The parameters with subscript '-exp' are the ones obtained from experimental data from (Darmawan \& Stewart, 2007): $i_{\text {corr-exp }}=186 \mu \mathrm{A} / \mathrm{cm}^{2}, T_{0 \text {-exp }}=0.03836$ years, $\mu_{0 \text {-exp }}=0.84, L_{\text {0-exp }}=650 \mathrm{~mm}$ and $\alpha_{0 \text {-exp }}=$ 8.10. The distribution of the maximum pit depth given by equation (7) can be used to generate samples of the pit depth in a probabilistic analysis of the corrosion process and corresponding resistance or probability of failure. The samples of the pit depth can subsequently be inserted in equation (2). This model of (Darmawan \& Stewart, 2007) is also applied by (Tu et al., 2019).

For these different models, a comparison is made of the predicted pit depth. The mean value of the pit depth $p(t)$ (or $a$ ) as a function of time is plotted for: 
1. The Gumbel distribution according to Stewart (2009) for bars with diameter $10 \mathrm{~mm}$ (the smallest value for which a distribution is proposed), with mean value of 5.65 for $R$;

2. The truncated normal distribution with mean value of 3 for $R$;

3. The Gumbel distribution proposed by (Darmawan \& Stewart, 2007) directly modelling the pit depth $p(t)$.

The mean pit depth as a function of time is given in Figure 1 . These results are generated for $i_{\text {corr }}=1 \mu \mathrm{A} / \mathrm{cm}^{2}$, $D_{0}=4.1 \mathrm{~mm}$ (diameter of a wire) and $T_{i}=20$ years. It can be seen that the first model gives a very fast increase in pit depth. This because there is a faster propagation of corrosion in reinforcement bars (see Table 1), for which this formulation was developed. The model of the truncated normal distribution gives a slower increase in pit depth, but still much larger than the distribution from equation (7). Since the latter is derived for the particular case of prestressing wires, it seems best to use this model in order not to overestimate the pit depth of the prestressing wires. The different models are also compared in Figure 2.

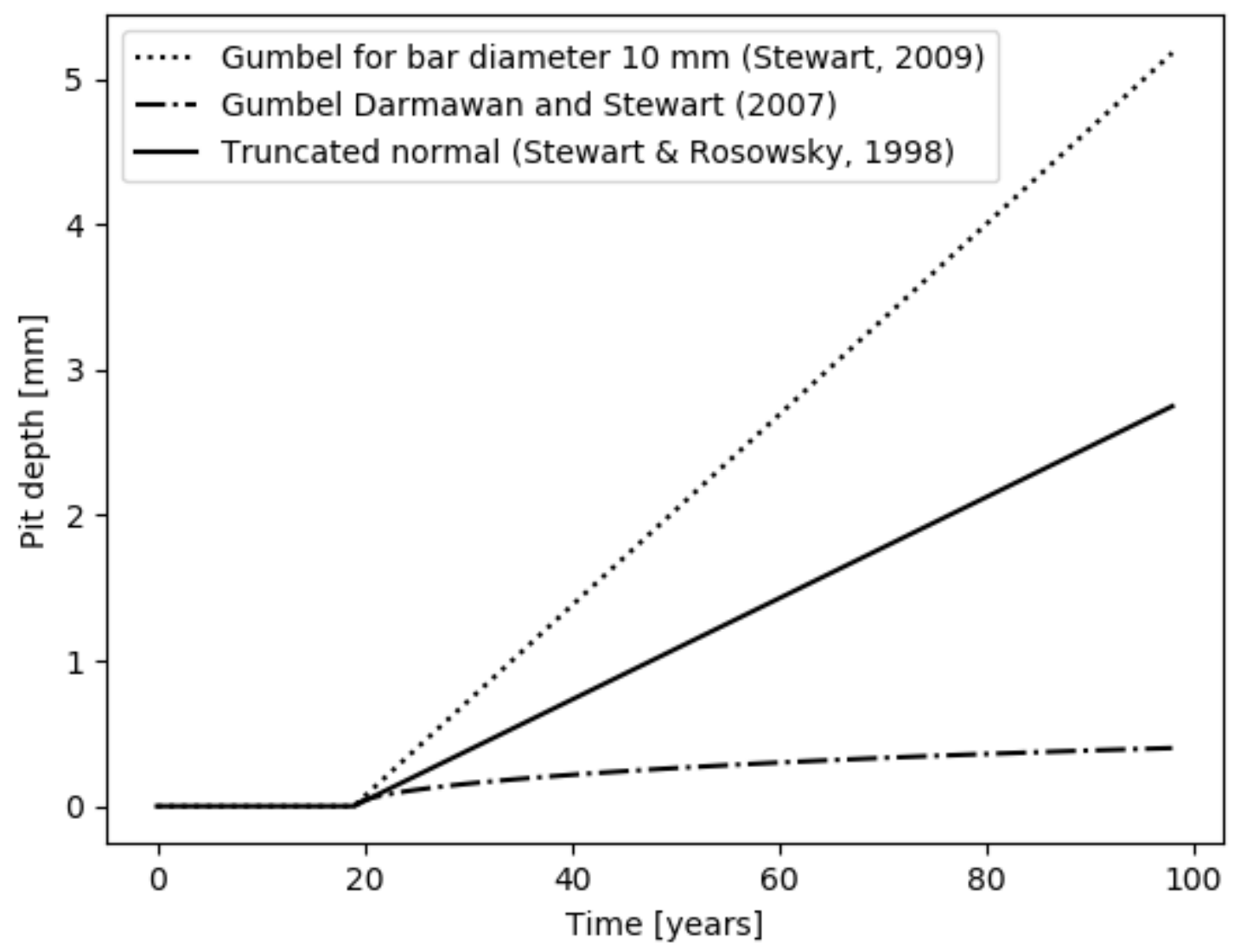

Figure 1 Pit depth as a function of time for different models found in literature 


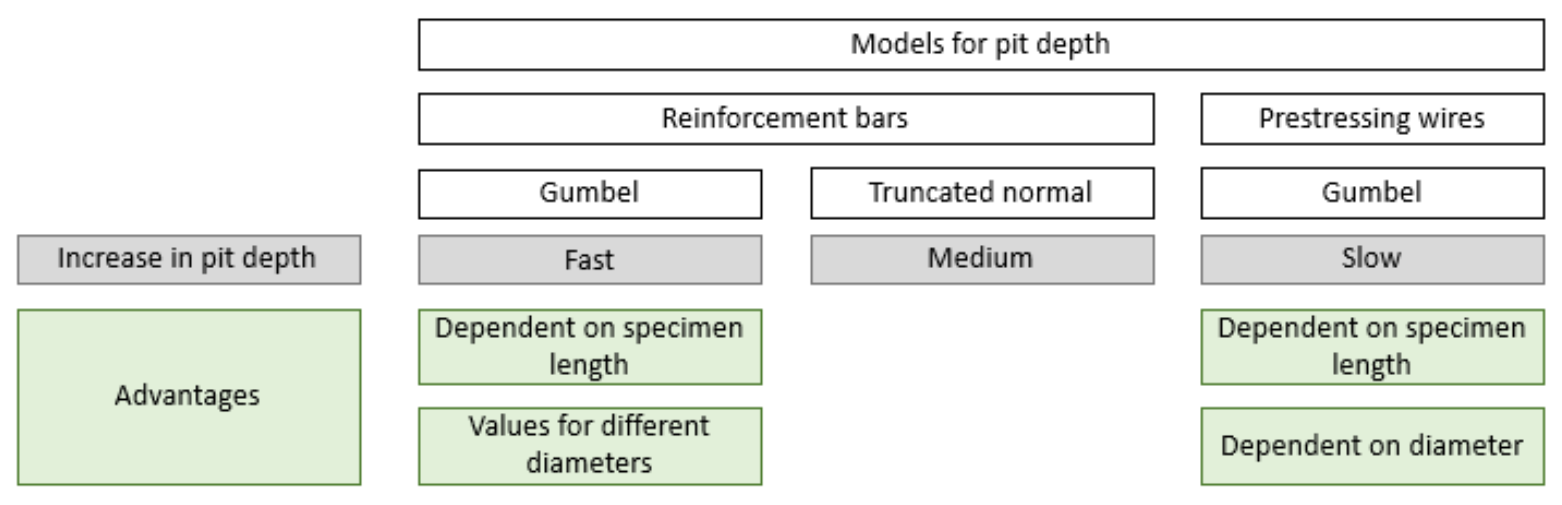

Figure 2 Comparison of different models for pit depth

It is generally assumed that pitting corrosion will only occur on the exposed surface of the strands, i.e. half of the total surface of the outer six wires (Guo et al., 2016; Tu et al., 2019). This area exposed to pitting corrosion is visualized in Figure 3. The pitting corrosion starts at these outer wires of a 7-wire strand since they are exposed to the chlorides. Hence, according to (Guo et al., 2016), the following assumptions can be made:

1. Neglect pitting corrosion of the inner wire;

2. Pitting corrosion on the outer six wires can occur at slightly different points in time;

3. The pits propagate slower than in reinforcing bars due to the high quality of the steel and the more strict manufacturing process.

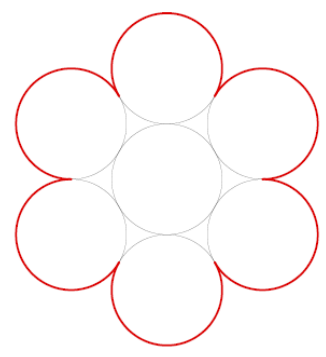

Figure 3 Area of a prestressing strand exposed to pitting corrosion (indicated with a red bold line)

\subsubsection{Carbonation-induced corrosion}

If corrosion due to carbonation and chlorides are both likely to occur, the reduction in resistance due to pitting corrosion will be more significant compared to the uniform corrosion resulting from carbonation. However, this depends on the environmental conditions, with some structures only exposed to carbonation risks.

In (Guo, Frangopol, et al., 2011), the initiation period for carbonation induced corrosion [years] is estimated by equation (12).

$$
T_{i}=\left[\frac{X-x_{0}}{k}\right]^{2}
$$

Here, $X$ is the concrete cover [mm], $x_{0}$ the remaining carbonation thickness [mm] and $k$ a carbonation coefficient. The latter two parameters are given by equations (13) and (14) respectively.

$$
\begin{gathered}
x_{0}=4.86\left(-R H^{2}+1.5 R H-0.45\right)(X-5)\left(\ln f_{c k}-2.3\right) \\
k=3.07 k_{j} k_{\mathrm{CO}_{2}} k_{s} \sqrt[4]{T}(1-R H) R H\left(\frac{57.94 m_{c}}{f_{c}}-0.76\right)
\end{gathered}
$$

Here, $f_{c}$ is the cubic concrete compressive strength [MPa], $m_{c}$ the ratio between the cubic compressive strength and its standard value, $R H$ the relative humidity [\%] and $T$ the ambient temperature $\left[{ }^{\circ} \mathrm{C}\right]$. The parameter $k_{j}$ accounts 
for the position of the reinforcement, $k_{C O 2}$ is determined by the concentration of $\mathrm{CO}_{2}$ and $k_{s}$ equals 1.1 to account for concrete stress (tension).

Equation (12) is based on Fick's first law and the initial model proposed by Tuutti (1982), where the carbonation rate is proportional to the square root of the time of exposure to $\mathrm{CO}_{2}$ :

$$
x=K \sqrt{t}
$$

Here, $x$ is the carbonation depth [mm], $K$ the carbonation coefficient $\left[\mathrm{mm} / \mathrm{year}^{-1 / 2}\right]$ and $t$ the exposure time to $\mathrm{CO}_{2}$ [year]. The parameter $K$ is very hard to estimate and is in for example (Monteiro, Branco, Brito, \& Neves, 2012) obtained based on regression analysis.

In (LNEC E-464, 2005), another formulation for the initiation period is proposed:

$$
x=\sqrt{\frac{2 \cdot c \cdot t}{R_{c 65}}}\left[\sqrt{k_{0} k_{1} k_{2}}\left(\frac{1}{t}\right)^{n}\right.
$$

Here, $c$ is the environmental carbon dioxide concentration $\left[\mathrm{kg} / \mathrm{m}^{3}\right], R_{c 65}$ the carbonation resistance coefficient $[\mathrm{kg}$ year $/ \mathrm{m}^{5}$ ] (to be determined from accelerated carbonation tests), $k_{0}$ a factor equal to 3 for specified test conditions, $k_{2}$ a factor equal to 1 for standard curing and equal to 0.25 for formwork with controlled permeability and 3 days curing, and $n$ is a factor taking into account the influence of wetting/drying over time.

According to (fib, 2006), the initiation period for carbonation induced corrosion can be derived from equation (17), assuming that corrosion will initiate as soon as the carbonation front has reached the reinforcement.

$$
c=\sqrt{2 k_{e} k_{c}\left(k_{t} R_{A C C}^{-1}+\varepsilon_{t}\right) C_{s}} \sqrt{t} W(t)
$$

Here, $c[\mathrm{~mm}]$ is the concrete cover, $R_{A C C^{-1}}\left[\left(\mathrm{~mm}^{2} / \mathrm{years}\right) /\left(\mathrm{kg} / \mathrm{m}^{3}\right)\right]$ is the inverse effective carbonation resistance of concrete and $C_{s}\left[\mathrm{~kg} / \mathrm{m}^{3}\right]$ the $\mathrm{CO}_{2}$-concentration. The factor $k_{e}[-]$ is an environmental function and is given by equation (18).

$$
k_{e}=\left(\frac{1-\left(\frac{R H_{\text {real }}}{100}\right)^{f_{e}}}{1-\left(\frac{R H_{\text {ref }}}{100}\right)^{f_{e}}}\right)^{g_{e}}
$$

Here, $R H_{\text {real }}[\%]$ is the relative humidity of the carbonated layer, $R H_{r e f}[\%]$ the reference relative humidity and $g_{e}$ and $f_{e}$ are exponents according to (fib, 2006).

The factor $k_{c}[-]$ in equation (17) is an execution transfer parameter and is equal to $k_{c}=\left(\frac{t_{c}}{7}\right)^{b_{c}}$. Here, $b_{c}[-]$ is an exponent of regression and $t_{c}$ [days] is the period of curing.

The function $W(t)$ in equation (17) is given by equation (19).

$$
W(t)=\left(\frac{t_{0}}{t}\right)^{w} \text { with } w=\frac{\left(p_{S R} T o W\right)^{b_{w}}}{2}
$$

Here, $T o W[-]$ is the time of wetness, $p_{S R}[-]$ is the probability of driving rain, $b_{w}[-]$ is an exponent of regression and $t_{0}$ [years] is the time of reference.

Regarding the corrosion rate, in (Guo, Frangopol, et al., 2011) a distinction is made between the situations before and after spalling. The corresponding expressions for the corrosion rate are given by equations (20) and (21) respectively.

Here, $k_{c e}$ is a regional coefficient equal to 2 .

$$
\begin{gathered}
\lambda_{1}=46 k_{c r} k_{c e} \exp (0.04 T) X^{-1.36}(R H-0.45)^{2 / 3} f_{c}^{-1.83} \\
\lambda_{2}=\left\{\begin{array}{cl}
2.5 \lambda_{1} & \lambda_{1}>0.008 \\
4.0 \lambda_{1}-187.52 \lambda_{1}{ }^{2} & \lambda_{1} \leq 0.008
\end{array}\right.
\end{gathered}
$$

The diameter of the corroded reinforcement is then given by equation (22). 


$$
D(t)=\left\{\begin{array}{cc}
D_{0} & t<T_{i} \\
D_{0}-2 \lambda_{1}\left(t-T_{i}\right) & T_{i} \leq t \leq T_{i}+T_{c r} \\
D_{0}-2 \lambda_{1}\left(T_{c r}-T_{i}\right)-2 \lambda_{2}\left(t-T_{c r}\right) \geq 0 & T_{i}+T_{c r}<t
\end{array}\right.
$$

Here, $T_{c r}$ is the time to spalling and $D_{0}$ the initial diameter of the reinforcement [mm].

The reduction $x(t)$ in reinforcement radius can also be given by equation (23) (Duracrete, 2000; Lay, Schieß1, \& Cairns, 2003; Stewart \& Rosowsky, 1998).

$$
x(t)=V_{\text {corr }} \cdot \alpha_{p} \cdot\left(t-T_{i}\right)
$$

Here, $t$ is the age of the structure [years], $\alpha_{p}$ [-] is a pitting factor to take into account the non-uniform corrosion of the rebar and $V_{\text {corr }}$ is the corrosion rate, which can be written as $V_{\text {corr }}=V_{\text {corr }, a} \cdot T o W$, with $V_{\text {corr }, a}$ the mean corrosion rate when corrosion is active [mm/year] and ToW the time of wetness as a fraction of the year [-]. For carbonation induced corrosion, $\alpha_{p}$ can be taken equal to 2 according to (Duracrete, 2000). Probabilistic models for the carbonation rate and time of wetness for a sheltered and unsheltered exposure class can be found in (Lay et al., 2003).

\subsection{Influence on steel properties}

To account for the high stresses due to the reduction in wire sections (which might trigger structural collapse), an adapted stress-strain curve for the corroded steel can be used. Besides the size reduction of the strands, also the degradation in mechanical properties of the steel can be modelled, including:

1. Ductility decrease;

2. Change in elastic modulus;

3. Change in ultimate strength due to the stress concentration caused by pitting and/or the asymmetric tension due to an asymmetric corrosion distribution;

4. Change in ultimate strain;

5. Loss of yielding plateau and strain hardening region if the corrosion degree is larger than a critical value.

$\mathrm{Lu}, \mathrm{Li}, \&$ Zhao (2016) performed an investigation on the mechanical behaviour of prestressing strands subjected to chloride attack. The reduced elastic modulus, ultimate strength and ultimate strain of the prestressed strands are given by equations (24) to (26).

$$
\begin{gathered}
E_{s}^{*}=(1-1.8 \alpha(t)) E_{s} \\
f_{u}^{*}=(1-2.8 \alpha(t)) f_{u} \\
\varepsilon_{u}^{*}=(0.1+0.9 \exp (-20 \alpha(t))) \varepsilon_{u}
\end{gathered}
$$

Here, $\alpha(t)[-]$ is the corrosion degree at time $t$, calculated based on the strand area.

The model of ( $\mathrm{Lu}, \mathrm{Li}, \&$ Zhao, 2016) is based on experimental investigation of 14 sets of prestressing strands embedded in concrete with a concrete cover of $15 \mathrm{~mm}$. Corrosion was accelerated by alternating wetting and drying of the samples with a solution of 5\% sodium chloride. In addition, a constant current of $1 \mathrm{~mA} / \mathrm{cm}^{2}$ was applied. It should be pointed out that the latter is relatively large, since in general it is assumed in literature that for currents larger than $100 \mu \mathrm{A} / \mathrm{cm}^{2}$ (Bolzoni \& Gastaldi, 2020), the corrosion products formed are not the same as found under natural corrosion. The upper limit of $100 \mu \mathrm{A} / \mathrm{cm}^{2}$ corresponds to the maximum localized corrosion rate in practice.

When the corrosion degree is given in percent, the constitutive law of the prestressing steel is given by equation (27) for corrosion degrees smaller than $8 \%$ (Lu et al., 2016). If the corrosion degree exceeds $8 \%$, the hardening plateau disappears and the stress-strain curve only contains the elastic branch.

$$
\sigma(\varepsilon)=\left\{\begin{array}{cc}
E_{s}^{*} \varepsilon & \varepsilon \leq \varepsilon_{y}^{*}=\frac{0.85 f_{u}^{*}}{E_{s}^{*}} \\
0.85 f_{u}^{*}+\frac{0.15 f_{u}^{*}}{\varepsilon_{u}^{*}-\varepsilon_{y}^{*}}\left(\varepsilon-\varepsilon_{y}^{*}\right) & \varepsilon_{y}^{*} \leq \varepsilon \leq \varepsilon_{u}^{*}
\end{array}\right.
$$

This model of (Lu et al., 2016) is also applied to model a prestressed structure which was tested by Belletti, Vecchi, Bandini, Andrade, \& Montero (2020), with a good approximation between experiments and simulations.

It should be pointed out that the stress-strain diagram given by equation (27) is bilinear. In reality, the stress-strain diagram of prestressing steel is not bilinear and does not show a clear yielding point. When an analytical 
description of the stress/strain diagram is needed, (JCSS, 2001) suggests the use of a (modified) Ramberg-Osgood curve to account for the 'knee' in the stress-strain diagram. The bilinear relation of equation (27) is plotted on top of the test results of (Lu et al., 2016) in Figure 4. Here it can be seen that even though the actual relation is not bilinear, a quite good approximation is found. However, further research is required in relation to the impact of this approximation.

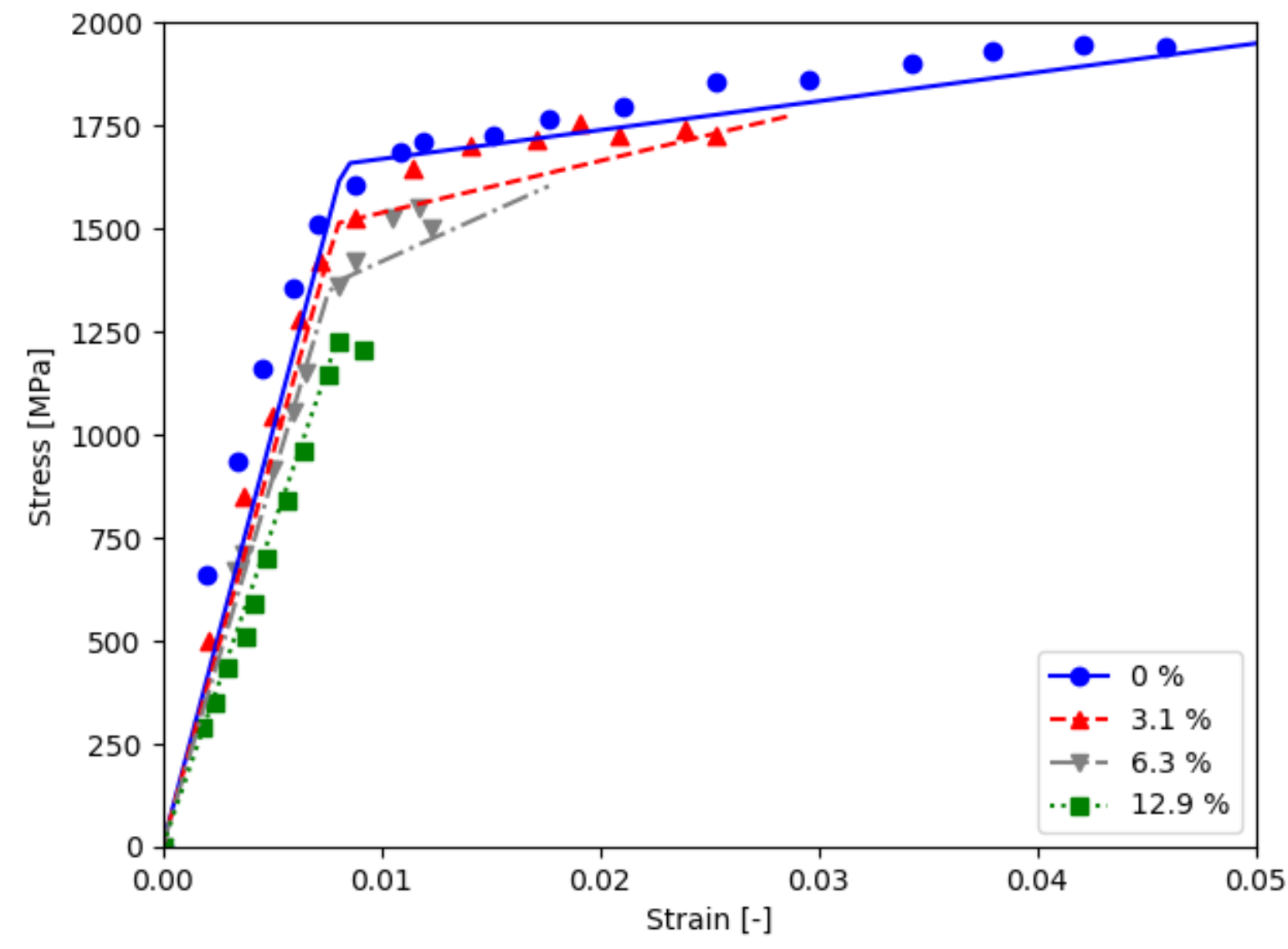

Figure 4 Approximation of the stress-strain curve by a bilinear diagram plot on the data of (Lu et al., 2016)

Model (27) is also applied by Jeon, Lee, Lon, \& Shim (2019). However, in the latter work, the ultimate stress and strain are determined based on a fit to data extracted from prestressing steel strands in external tendons of an existing bridge. The resulting models are given by equation (28) and (29). The regression coefficients depend on the pit depth and pit shape (corresponding to three types of pit configurations based on observations on real corroded strands).

$$
\begin{gathered}
f_{u}^{*}=a \alpha(t)+b \\
\varepsilon_{u}^{*}=\left\{\begin{array}{cc}
c \alpha(t)^{2}+d \alpha(t)+e & d_{p}<0.5 \\
f \alpha(t)^{g} & d_{p} \geq 0.5
\end{array}\right.
\end{gathered}
$$

Here, $d_{p}$ is the pit depth and $a$ to $g$ are regression parameters dependent on the pit shape, as given in Table 2 (Jeon et al., 2019). In expressions (28) and (29), the corrosion degree is calculated based on the wire area. 
Table 2 Regression coefficients to be used in the stress/strain model of (Jeon et al., 2019)

\begin{tabular}{|c|c|c|c|c|c|c|c|}
\hline \multirow{2}{*}{ Pit type } & \multicolumn{7}{|c|}{ Regression parameters } \\
\hline & $a$ & $b$ & $c$ & $d$ & $e$ & $f$ & $g$ \\
\hline Type 1 & -1991.8 & 1748.0 & -5.96 & -1.30 & 0.0754 & 0.0025 & -0.621 \\
\hline Type 2 & -1995.6 & 1801.6 & -1.00 & -0.69 & 0.0754 & 0.0045 & -0.305 \\
\hline Type 3 & -2302.7 & 1752.7 & 9.54 & -1.77 & 0.0754 & 0.0045 & -0.298 \\
\hline
\end{tabular}

Also Tu et al. (2019) apply the same constitutive law. However, equations (24) to (26) are slightly differently formulated, according to equations (30) to (32), where $\alpha(t)$ should be given as a percentage (percentage area loss caused by corrosion). The latter equations are formulated for prestressed tendons and not for strands; hence this might explain the difference compared to equations (24) to (26).

$$
\begin{aligned}
E_{s}^{*} & =(1-0.848 \alpha(t)) E_{s} \\
f_{u}^{*} & =\frac{(1-2.683 \alpha(t))}{1-\alpha(t)} f_{u} \\
\varepsilon_{u}^{*} & =(1-9.387 \alpha(t)) \varepsilon_{u}
\end{aligned}
$$

All the above-mentioned models give the reduced steel properties as a fraction of the initial value, i.e. the initial value multiplied by a reduction factor, where the latter is a function of the corrosion degree. The influence on the steel properties according to (Tu et al., 2019), (Lu et al., 2016) and (Jeon et al., 2019) (for pit type 1) is illustrated in Figure 5. For the ultimate strength of the steel, a value of $1748 \mathrm{MPa}$ is assumed (based on the value for $b$ in the formulations of (Jeon et al., 2019)). For the reduction of the Young's modulus, there is quite a large difference between the illustrated models. The reduction of the ultimate strength is quite similar for corrosion degrees up to $3.5 \%$ for the models of (Tu et al., 2019) and ( $\mathrm{Lu}$ et al., 2016). For higher corrosion degrees, (Tu et al., 2019) provides higher reduction factors. The reduction factors provided by (Jeon et al., 2019) are generally higher. There is also a difference in reduction factor for the ultimate strain, but this is smaller than for the Young's modulus. 

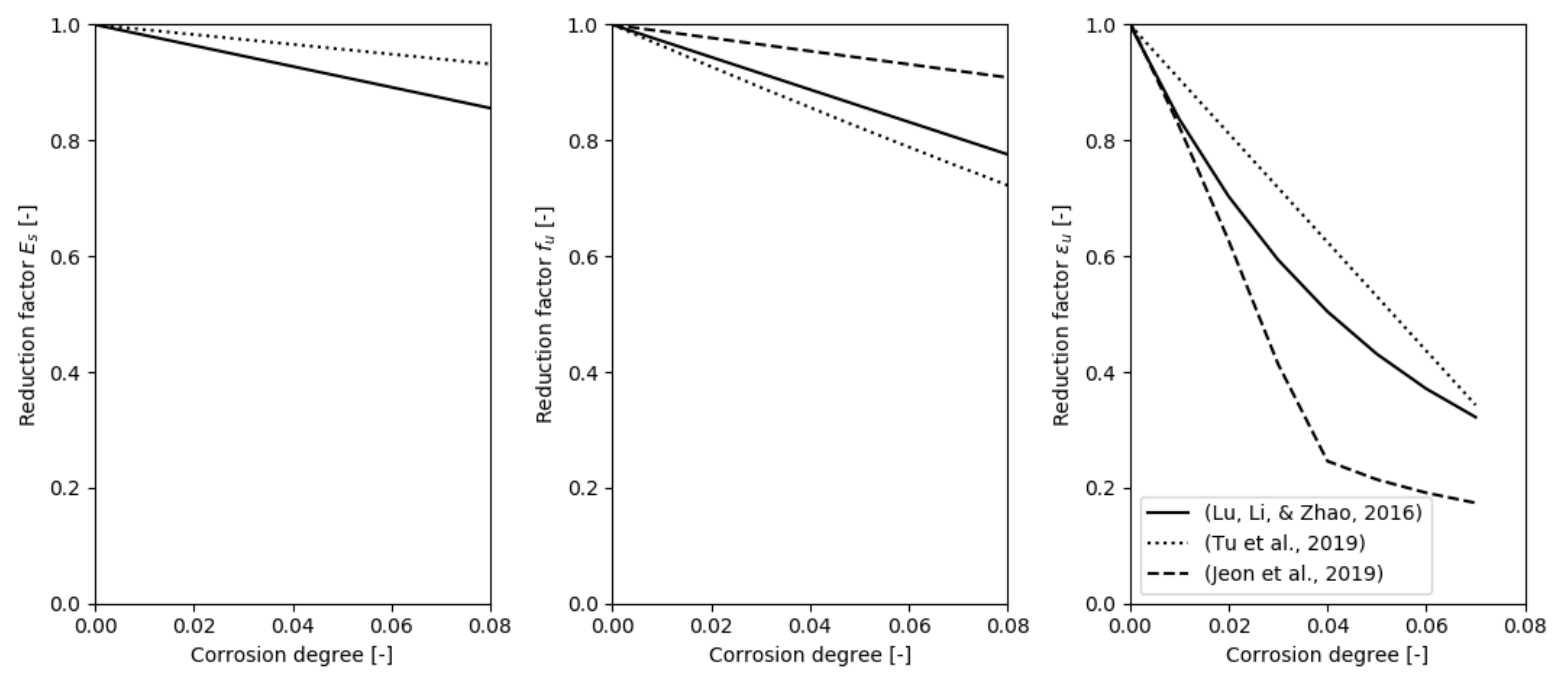

Figure 5 Influence of the corrosion degree on the steel properties according to different authors

Another constitutive law is used by Wang, Zhang, Zhang, Dai, \& Liu (2017). In this model, the hardening stage of the steel disappears for corrosion degrees larger than $11 \%$. This corrosion loss is calculated based on the strand area. The constitutive law is given by equation (33) for corrosion loss less than $11 \%$ and by equation (34) otherwise.

$$
\begin{gathered}
\sigma(\varepsilon)=\left\{\begin{array}{cl}
E_{s} \varepsilon & \varepsilon \leq \varepsilon_{y} \\
f_{y}+E_{p p}\left(\varepsilon-\varepsilon_{y}\right) & \varepsilon_{y} \leq \varepsilon \leq \varepsilon_{u}-\frac{\alpha(t)}{0.11}\left(\varepsilon_{u}-\varepsilon_{y}\right)
\end{array}\right. \\
\sigma(\varepsilon)=\left\{\begin{array}{cl}
E_{s} \varepsilon & \varepsilon \leq \varepsilon_{y} \\
0 & \varepsilon>\varepsilon_{y}
\end{array}\right.
\end{gathered}
$$

Here, $E_{s}$ is the elastic modulus, $E_{p p}$ the hardening modulus, $\varepsilon_{y}$ the yield strain, $\varepsilon_{u}$ the ultimate strain and $f_{y}$ the yield stress, all of the virgin strand. These equations are derived based on an experimental campaign where 7-wire strands (not embedded in concrete) are subjected to accelerated corrosion by applying a salt fog with 5\% sodium chloride at a temperature of $20^{\circ} \mathrm{C}$ and a relative humidity of $70 \%$. It should be pointed out that this model of (Wang, Zhang, et al., 2017) is conceptually very similar to the one of equation (27), since both include a bi-linear model with hardening. The main difference lies within the consideration that the plastic branch is lost at $11 \%$ of corrosion instead of $8 \%$. Both models are based on experimental results and hence the difference between $8 \%$ or $11 \%$ might be explained by scatter on the experimental results. Another explanation might be the difference in the samples or in the method applied for accelerating the corrosion process. (Wang et al., 2017) considers strands directly subjected to accelerated corrosion, whereas in the publication of Lu, Li \& Zhao (2016) the strands are embedded in concrete. Furthermore, in (Wang et al., 2017) the corrosion process is accelerated by a salt fog, whereas in ( $\mathrm{Lu}, \mathrm{Li} \& \mathrm{Zhao}, 2016)$ a current is applied to the strands and the concrete specimens are subject to alternating wetting and drying.

In Figure 6, a comparison of the different models for the influence of corrosion on the stress-strain diagram of prestressed steel can be found. 


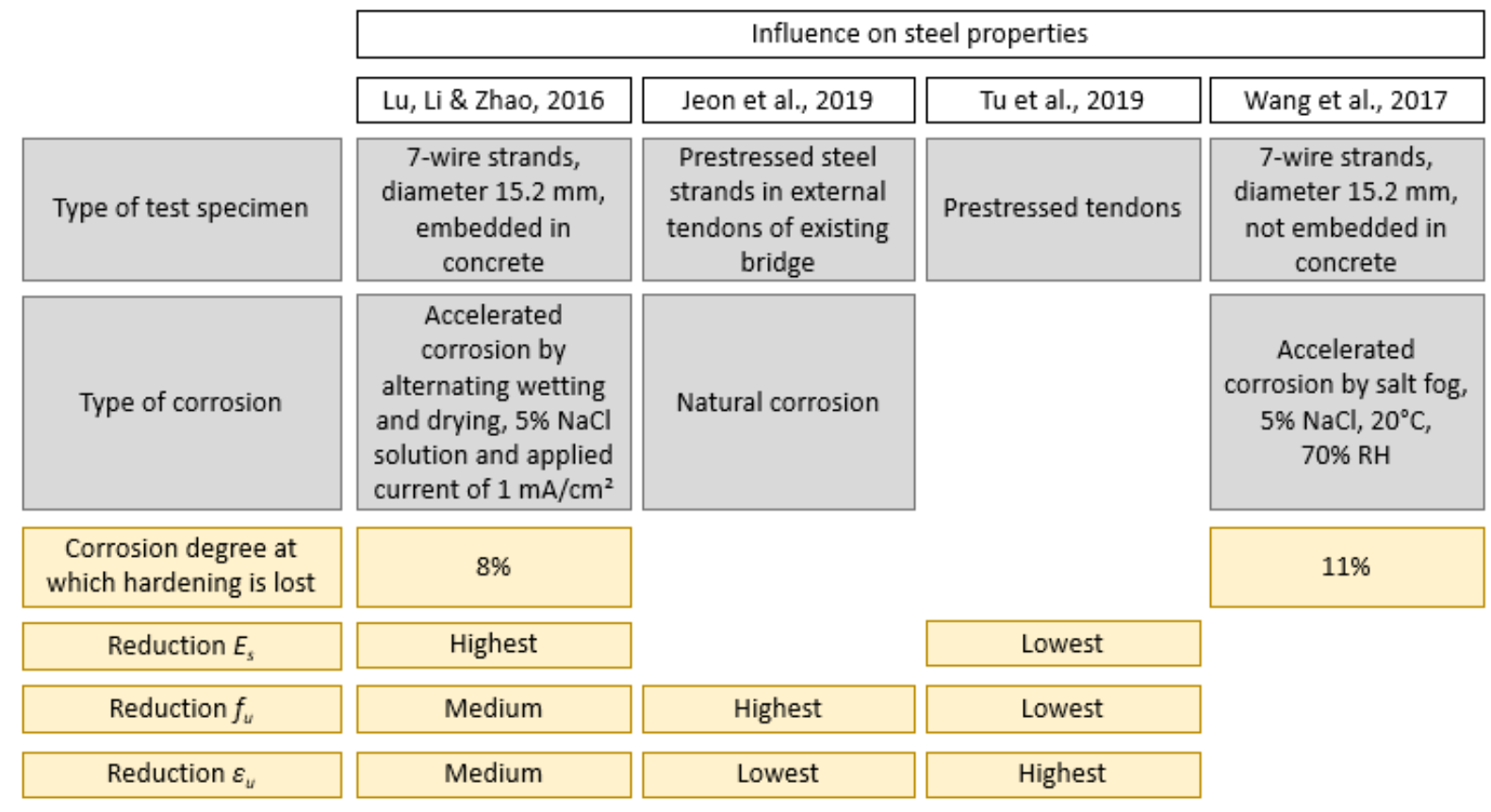

Figure 6 Comparison of different models for the stress/strain diagram of corroded prestressed reinforcement

It can be questioned whether the stress/strain relationship can be derived from accelerated corrosion tests and whether the behaviour may be different under natural corrosion. The accelerated corrosion behaviour of tendons subjected to high tensile stresses has not been thoroughly investigated yet. The applied current mainly influences the oxides formed during corrosion and the results affected by the formation of these oxides, e.g. cracking of the concrete. Since acceleration of corrosion by imposed current mostly influences the formed oxides, the experimental stress-strain diagrams resulting from accelerated corrosion tests might be a good approximation of the actual ones in natural conditions.

In (Malumbela, Moyo, \& Alexander, 2012), research on accelerated corrosion tests on reinforced concrete structures is summarized. One of the topics tackled in the paper is how the level of corrosion current density can influence the stiffness of RC specimens, the rate of widening of corrosion cracks, etc. However, some authors state an increased rate of widening of corrosion cracks for high current densities, while others report the same phenomenon for lower current densities.

Considering the influence on the stress-strain estimation of RC structures, other sources can be consulted. In (Kashani, Crewe, \& Alexander, 2013), experiments are performed on RC specimens. The relation between corroded and uncorroded yield strength or ultimate strength equals $1-0.015 \alpha$, with $\alpha$ the corrosion degree as a percentage. These results are based on accelerated corrosion tests with a current density of $2.4 \mathrm{~mA} / \mathrm{cm}^{2}$. In $(\mathrm{Du}$, Clark, \& Chan, 2005), accelerated corrosion tests are performed with current densities of $0.5,1$ or $2 \mathrm{~mA} / \mathrm{cm}^{2}$ depending on the diameter of the reinforcement. Here a ratio of $1-0.014 \alpha$ is found. These results are very similar to those of (Kashani et al., 2013). Finally, in (Cairns, Plizzari, Du, Law, \& Franzoni, 2005), a summary is given of the reduction factors found in existing literature up to then for different experiments, i.e. different ways of accelerating corrosion and different current densities. One of the conclusions in (Cairns et al., 2005) is that one study, might indicate that accelerated corrosion produces more uniform section loss than corrosion under service conditions.

These results are obtained from experiments on RC specimens. The influence of accelerated corrosion might be similar for PC and RC structures. Nevertheless, experimental results should always be interpreted with care and extra investigation on the influence of the applied current on the stress-strain relationship might be an interesting topic for further research.

The influence of corrosion on the yield stress at time $t$ can for example be modelled according to equation (35).

$$
f_{y}=(1-a \cdot \alpha(t) \times 100) f_{y 0}
$$

Here, $f_{y 0}$ is the initial yield stress and $a$ an empirical coefficient $(0.0054$ for reinforcing bars and 0.0075 for stranded wires (Du et al., 2005; Vu et al., 2009)). However, Zhang, Wang, Zhang \& Liu (2017) state that the effect of 
corrosion loss on the yield stress and Young's modulus is limited when compared to the effect on the ultimate strain of the strands. This can for example be illustrated when applying equation (35) for a corrosion degree of $0.08(8 \%)$, which leads to a reduction factor on the yield stress of 0.94 , which is much higher than the factors in Figure 5 and hence causes a smaller reduction.

\subsection{Influence on concrete}

Corrosion of steel can also lead to cracking of the surrounding concrete, leading to a loss of compressive strength and a reduced stiffness of the damaged concrete. Corrosion of reinforcement can also induce a reduction in bond between steel and concrete. However, when considering the reduction of bond at the steel/concrete interface, pitting corrosion is less likely to disrupt the concrete cover and reduce the bond strength around the pits, due to its local character. This is illustrated by the work of Belletti et al. (2020), who found that a model without a deteriorating bond-slip relation was able to give a good approximation of the load-displacement curve and the localization of failure. Furthermore, Wang, Yi, Zhang, Jiang, \& Zhang (2017) have shown that the presence of stirrups can induce a delay in bond deterioration and can enhance the bond strength by about $25 \%$ compared to a case without stirrups. Moreover, they pointed out that the most important phenomenon inducing bond deterioration is corrosion-induced concrete cracking, and the reduction in bond strength only manifests during this first cracking stage, after which it stabilizes. The corrosion-induced concrete cracking should preferably be accounted for when investigating stiffness related parameters such as deformations of the structure.

In (Belletti et al., 2020), the reduction in concrete compressive strength due to corrosion is modelled according to equation (36) (Coronelli \& Gambarova, 2004).

$$
f_{c}^{*}=\frac{f_{c}}{1+K \frac{\varepsilon_{1}}{\varepsilon_{c 0}}}
$$

Here, $K$ is a coefficient related to the bar roughness and diameter ( 0.1 for medium-diameter ribbed bars), $\varepsilon_{c 0}$ is the strain at the peak compressive stress $f_{c}$ and $\varepsilon_{l}$ is the average (smeared) tensile strain in the cracked concrete perpendicular to the applied compression. This last term is given by equation (37) (Coronelli \& Gambarova, 2004).

$$
\varepsilon_{1}=\frac{n_{\text {bars }} w_{c r}}{b_{0}}
$$

Here, $b_{0}$ is the initial concrete section width before degradation due to corrosion, $n_{\text {bars }}$ is the number of reinforcement bars in the compression zone of the concrete and $w_{c r}$ is the total crack width for a given corrosion level. This crack width can be evaluated by applying equation (38) (Andrade, Alonzo, \& Molina, 1993).

$$
w_{c r}(t)=2 \pi\left(v_{r s}-1\right) x(t)
$$

Here, $x(t)$ is the depth of the corrosion attack and $v_{r s}$ is the ratio of volumetric expansion of the oxides formed as corrosion products with respect to the virgin material, typically taken equal to 2 for reinforcement steel (Andrade et al., 1993). The chemical composition of prestressing strands differs from the one of reinforcement bars. This might lead to different expansion ratios for prestressing and ordinary reinforcement steel (Li et al., 2011). Moreover, due to the different shape of, for example, 7-wire strands compared to reinforcement bars, the formed cracking pattern might be different since the pressure generated by the corrosion products will have a different distribution. Nevertheless, the purpose of this equation is not to model the actual cracking pattern, but to provide an estimate of the influence on the concrete parameters. Whereas it seems reasonable to apply the given equation as a rough estimate of this reduction, a more detailed investigation on this topic might be required.

The reduced stiffness of the concrete due to corrosion cracking can be evaluated based on equation (36) since the Young's modulus of the concrete can be modelled as a function of the concrete compressive strength. Examples can be found in $(\mathrm{CEN}, 2005)\left(E_{c}=22\left(\frac{f_{c}}{10}\right)^{0.3}\right.$, with $f_{c}$ in MPa $)$ and $(\mathrm{Lv} \& \mathrm{Zhu}, 2016)\left(E_{c}=4500 \sqrt{f_{c}}\right)$. Inserting the reduced concrete compressive strength according to equation (36) leads to a reduced Young's modulus accounting for corrosion.

Considering prestressed structures, in (Dai, Wang, Zhang, \& Zhang, 2015) a formulation for the critical crosssection loss at the cover cracking stage is given according to (39).

$$
\rho_{p}=\frac{4\left[\pi R_{0}^{2}-\pi\left(R_{0}-\delta_{p}\right)^{2}\right]}{A_{p}}
$$

Here, $R_{0}$ is the radius of the wire before corrosion, $A_{p}$ the strand cross-sectional area and $\delta_{p}$ the critical radius loss at cover cracking, as given by equation (40). 


$$
\delta_{p}=k_{1}\left(R_{0}-\sqrt{R_{0}^{2}-\frac{V_{C}}{4 \pi(n-1)}}\right.
$$

Here, $n$ is the rust expansion ratio and $k_{l}$ a coefficient to consider the filling extent of corrosion products before cover cracking. The latter is assumed similar for reinforcement corrosion and equal to 0.2 . $V_{C}$ is the total volume of internal cracks. Assuming a triangular shape and a crack length that extends to the concrete surface, $V_{C}$ is given by equation (41).

$$
V_{C}=\frac{1}{2} C \sum w_{i}=\frac{1}{2} C \cdot 8 \pi(n-1) \delta_{m}
$$

Here, $C$ is the concrete cover and $\delta_{m}$ the radial loss at the microcracking stage.

The disadvantages of the model of (Dai et al., 2015) are the fact that the reinforcement expansion ratio of rust is used, residual stiffness of cracked concrete is not considered and two independent theories are used for crack initiation (a mechanical model) and propagation (a geometrical model). To resolve these issues, Wang et al. (2019) investigated the cracking of concrete under combined prestress and strand corrosion. The resulting rust expansion ratios were found to be on average equal to 2.78. Since in the experiments low corrosion degrees already induced cracking and corrosion is more uniform for low corrosion degrees, uniform corrosion products are assumed in the prediction model of Wang et al. (2019). However, it should be pointed out that this not necessarily corresponds to reality. The model is based on the thick-walled cylinder theory, and accounts for filling of cracks and pores. The residual tangential stiffness in cracked concrete assuming uniformly distributed smeared cracks is indicated by $a$. The relation between corrosion loss of the strand and the stiffness reduction of the concrete is given by equation (42).

$$
\rho=\frac{4 \pi\left(R_{u}+R_{0}\right)\left[b_{1}\left(R_{t}\right) R_{t}^{\sqrt{a}}+b_{2}\left(R_{t}\right) R_{t}^{-\sqrt{a}}\right]}{(n-1) A_{p}}
$$

Here, $R_{u}$ is the radius of the cracked region within the concrete. If cracks reach the surface, $R_{u}$ equals $R_{c}$, which is the distance between the centre of the outer wire and the concrete surface. $R_{t}$ is the radius of the wire with corrosion products, accounting for the rust expansion ratio $n . A_{p}$ is the initial strand cross-sectional area. The factors $b_{1}$ and $b_{2}$ are given by equation (43).

$$
b_{1}(r)=\frac{\left(1-v_{c}\right) m+P_{u}\left(1-v_{c}^{2}\right) /\left(\sqrt{a} E_{c}\right)}{2 R_{u}^{\sqrt{a}-1}} ; b_{2}(r)=\frac{\left(1+v_{c}\right) m+P_{u}\left(1-v_{c}^{2}\right) /\left(\sqrt{a} E_{c}\right)}{2 R_{u}^{-\sqrt{a}-1}}
$$

Here, $v_{c}$ is the Poisson's ratio of the concrete and $E_{c}$ its Young's modulus. The parameter $m$ is given by equation (44). $P_{u}$ is the expansive pressure at the interface between the cracked and uncracked concrete regions and is also given by equation (44).

Here, $f_{t}$ is the tensile strength of the concrete.

$$
m=\frac{\left(1+v_{c}\right) f_{t}}{E_{c}+\left(R_{c}^{2}+R_{u}^{2}\right)}\left[R_{c}^{2}+\left(1-2 v_{c}\right) R_{u}^{2}\right] ; P_{u}=f_{t} \frac{R_{c}^{2}-R_{u}^{2}}{R_{c}^{2}+R_{u}^{2}}
$$

The corrosion degree $\rho$ is calculated according to equation (45).

$$
\rho=\frac{4 \pi\left(R_{0}^{2}-R_{\rho}^{2}\right)}{A_{p}}
$$

Here, $R_{\rho}$ equals the wire radius after corrosion assuming that only the outer surface of the 7-wire strand corrodes.

It should be pointed out that the model of Wang et al. (2019) does not account for the presence of multiple strands and when the calculated crack widths were compared to experimental results, the error equals $11 \%$ on average. It should be pointed out that this error is due to both model and measurement errors. Moreover, when trying to solve the given equations to the stiffness reduction factor $a$, unrealistic values are found and results of the article of Wang et al. (2019) cannot be reproduced. Probably there is a minor error in one of the equations, for example in the equations for $b_{1}$ and $b_{2}$ since these are not a function of $r$.

The different models summarized in this section are compared in Figure 7. 


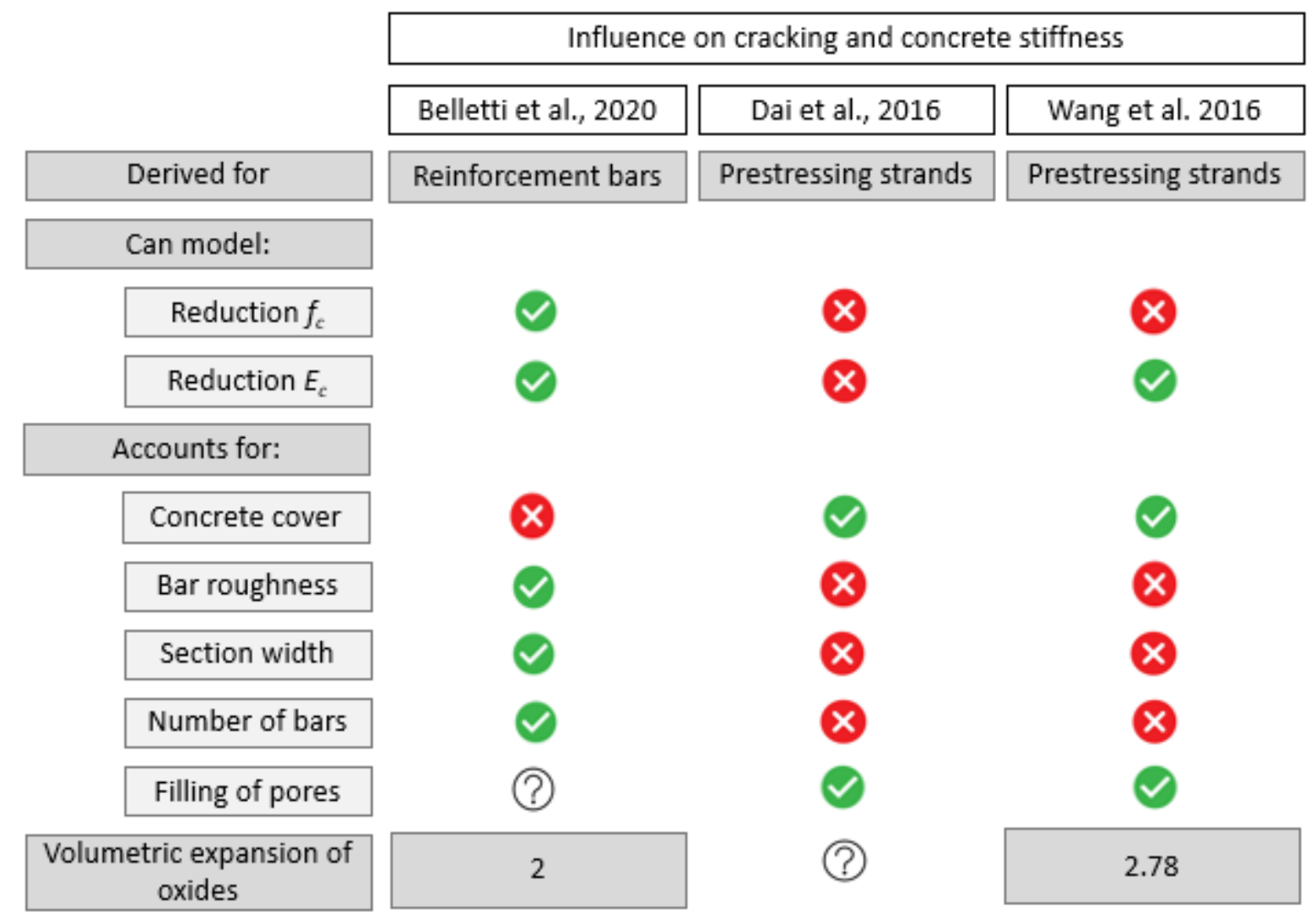

Figure 7 Comparison of different models for the influence of corrosion on concrete cracking and stiffness

\subsection{Spatial modelling of pitting corrosion}

When pitting corrosion occurs, the pits will be distributed along the wires, with different pit depths on the wires, even at the same location along the strand. Therefore, Darmawan \& Stewart (2007) subdivided the considered beams in different elements, with element lengths equal to two times the development length of the bond between steel and concrete. This element length is based on the assumption that when failure of the steel occurs, there will be a loss of capacity at a distance equal to this development length at either side of the fracture since the bond strength has to redevelop starting from the location of fracture. Assigning the element length equal to two times the development length of the bond is based on the assumption that failure occurs in the middle of the elements. In reality, strand failure could occur near element sides with higher or lower action effects, inducing reduced or increased reliabilities. Nevertheless, it is assumed that differences in reliabilities for non-central strand ruptures will level out, leading to similar reliabilities at the level of the structure when compared those obtained from the proposed failure criterion.

Dias-da-Costa et al. (2019) also account for the fact that pitting can vary in space. To model the spatial variability, they divide the reinforcement into different segments, with different pit depths for each segment. For this purpose, the ratio between maximum and average pit depth $R$ is randomly generated. A Gumbel distribution is assigned to $R$ with parameters $u=5.56$ and $\alpha=1.16$ based on (Stewart \& Al-Harthy, 2008), where these values were experimentally derived for RC beams. All segments are considered statistically independent. The resistance capacity of the strands is then governed by the tensile capacity of each segment, depending on the reduced prestressing area. In contrast to Darmawan \& Stewart (2007) who define the discretization length based on the transfer length of the prestressing force to the concrete, Dias-da-Costa et al. (2019) define the discretisation length as the distance at which pitting corrosion influences the structural safety, i.e. in the range of 0.1 to $1 \mathrm{~m}$. The latter means that the reliability index cannot suddenly drop at the onset of corrosion. Taking this constraint into consideration, Dias-da-Costa et al. (2019) selected an element length of $0.45 \mathrm{~m}$ for the structure under consideration, which is indeed between the suggested element lengths of 0.1 and $1 \mathrm{~m}$.

When comparing both models for the spatial variability, some observations can be made. For example, when an accurate estimate of the reliability index is required, the element lengths assumed by Darmawan \& Stewart (2007) might be too large and can result in an underestimation or overestimation of the reliability index because of the mentioned possibiltiy of non-central strand ruptures and the assumed statistical independence of the segments. The 
criterion suggested by Dias-da-Costa et al. (2019) will lead to more accurate reliability estimates but at the cost of requiring small element lengths leading to higher computational costs. Hence, the engineer should consider all of these aspects when making decisions on the element length.

The different aspects are summarized in Figure 8.

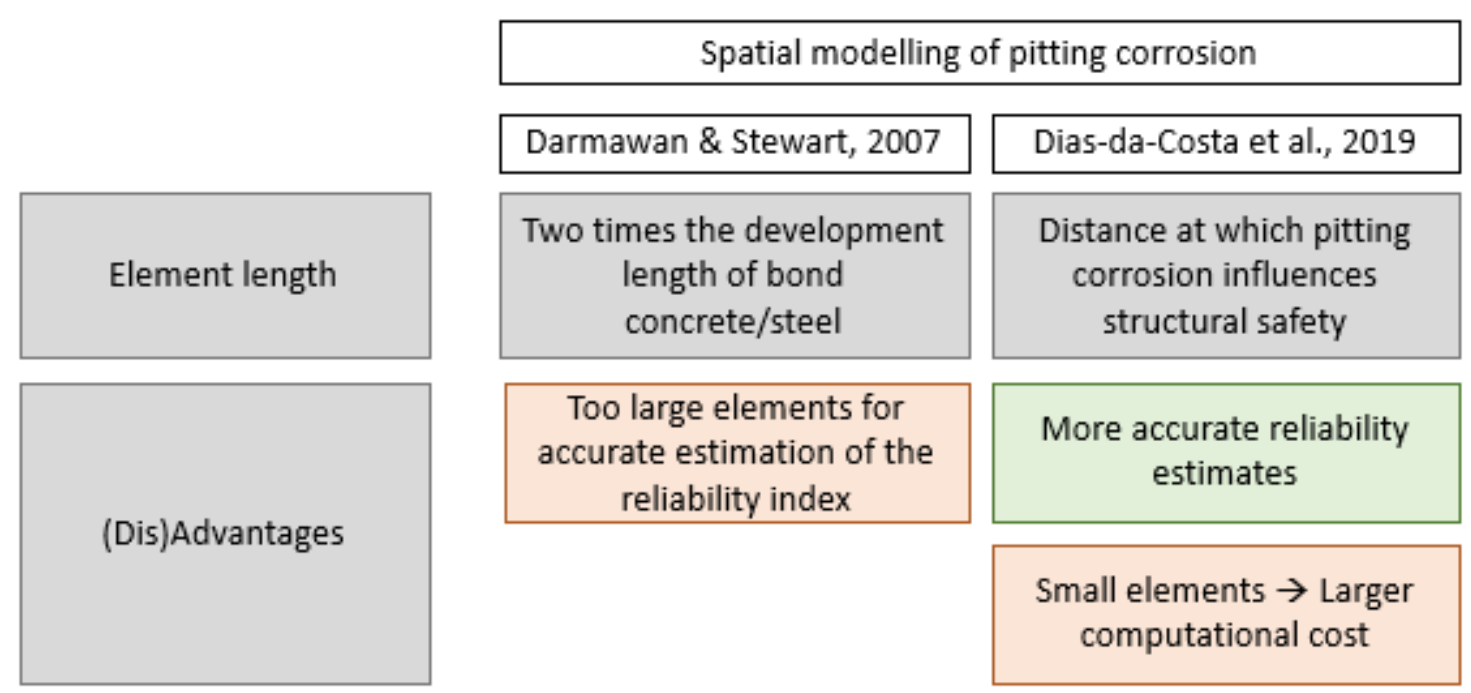

Figure 8 Comparison between two models to account for the spatial variation of pitting corrosion

The effect of spatial distribution of pitting in PC beams was also studied in (Belletti, Corres Peiretti, et al., 2020). Here it was demonstrated that the knowledge of the actual corrosion distribution over the length of the PC beam is fundamental for a reliable prediction of the ultimate limit state. Moreover, assumptions regarding the spatial distribution of pitting corrosion might also affect the location of the section where failure takes place.

Methods to account for the spatial variation of corrosion in post-tensioned elements are described in section 4 .

\subsection{Finite Element Modelling}

Guo et al. (2011) created a finite element model of a prestressed concrete box-girder bridge. The model consisted of shell elements because of their computational efficiency. With degenerated shell elements (DIANA FEA BV, 2019), the post-cracking behaviours of PSC box-girders could be simulated effectively. The conventional reinforcement was modelled with reinforcement grids, embedded in the concrete. The tendons were inserted by adding a few location points and describing the tendon shape between these points by shape functions. Structural interface elements were used to model the bond-slip relation between steel and concrete, which is suggested when the element is loaded in a regime with a highly non-linear behaviour. The tension softening of the concrete was modelled by a Hordijk curve and a bilinear kinematic hardening model was applied for the steel. A reduction of prestress reinforcement due to corrosion was modelled by a reduction in steel section. For the studied application, Guo et al. (2011) found that the total strain rotational crack model provides a better prediction of girder deflections compared to fixed crack models. The analysis was performed in DIANA FEA, where aggregate interlocking is accounted for based either on empirical crack models, or by physical models. Examples of the applied empirical models are the rough crack models of (Bazant \& Gambarova, 1980; Gambarova \& Karakoç, 1983) and the aggregate interlock relation of (Walraven \& Reinhardt, 1981; Walraven, Vos, \& Reinhardt, 1979). Examples of physical crack models are the two-phase model of (Walraven, 1980) or the contact density model of (N. Li, Maekawa, \& Okamura, 1989).

It should be pointed out that the capacity to predict the behaviour of PC beams does not only depend on the type of crack models, but also on the models used to describe several other non-linear phenomena. For example, in (Belletti, Vecchi, et al., 2020), for the FEM model of the PC beams adopting membrane elements, a selfimplemented fixed crack model, called PARC_CL (Belletti, Scolari, \& Vecchi, 2017; Vecchi, Belletti, \& Imperia, 2020 ) is used, where the aggregate interlock is modelled for static and cyclic loading. The PARC_CL model is based on a total strain fixed crack approach. In (Belletti, Vecchi, et al., 2020) a damage model for the material behaviour of the prestressing strands is implemented according to section 3.2 to account for the influence of corrosion (i.e. a reduced Young's modulus, ultimate strength and ultimate strain of the steel). Both a smeared approach (assuming perfect bond) and a discrete modelling approach of the strands were applied. In the latter, the 
bond-slip relation in corroded conditions was accounted for. The normal reinforcement was modelled as smeared. The performed analysis is displacement-controlled, with an implicit solution method and Newton Raphson iteration scheme. The influence of corrosion on the mechanical properties of concrete is accounted for by reducing the concrete compressive and tensile strength at the elements located at the splitting cracks and by reducing the aggregate interlock at these locations with $70 \%$ to account for the effect of corrosion on the concrete resistance.

Bagge, Plos, \& Popescu (2019) investigated a prestressed concrete bridge and tested it to failure. The corresponding finite element model consists of a combination of shell, beam, solid and truss elements. The nonprestressed reinforcement is modelled as embedded reinforcement and the material models are linear. Only in regions where cracking and a non-linear compressive response is expected, non-linear material models are used. Existing cracks are either modelled by a local reduction in Young's modulus, tensile strength and fracture energy of the concrete, or by simulating crack formation by imposing loads. The smeared crack approach is used and for concrete, the strain decomposition concept is applied with a Hordijk curve after crack initiation. Concrete in compression is modelled by a strain-based parabolic ascending branch for the hardening stage and a displacement based linear descending branch for softening. A rotating to fixed crack model is applied. Steel is modelled with a multilinear stress/strain diagram accounting for post-yield hardening. Bond-slip relation is not implemented since crack widths, member ends or anchor regions were not the focus of the analysis. As a non-linear solver, a modified Newton-Raphson scheme is used. The nonlinear finite element analysis of Bagge, Plos, \& Popescu (2019) accurately reproduced the experimental behaviour, capturing the actual failure mechanism and load-carrying capacity with less than $4 \%$ deviation.

When developing a finite element model, the purpose of the model should be kept in mind. This can be prediction of the ultimate capacity, of serviceability limit states, etc. For most practical cases, the bond-slip behaviour between strands and concrete should not necessarily be accounted for (Belletti et al., 2020;Darmawan, 2009) and the prestressing strands can be modelled as embedded reinforcement. If the geometry and level of detail allow such simplification, a lot of computational time can be saved by using a 2D model instead of a 3D model. Nevertheless, for complex bridge geometries, a 3D model can be necessary, where often computational time is saved by using a coarse overall mesh, with local refinements in the critical regions (Bagge et al., 2019). If thinwalled concrete structures are to be modelled, such as box girders, shell elements can be used rather than solids.

\section{ASSESSMENT OF POST-TENSIONED STRUCTURES}

There are some important differences between pre-tensioned and post-tensioned structures, which might influence their assessment. The most important difference between both types of structures is the presence of a duct in which the tendons are located, which implies that they are not in direct contact with the concrete. Hence, initiation of corrosion is not determined by the same processes as for reinforced and pre-tensioned structures. In the following section, information is provided on how to account for corrosion in post-tensioned structures.

Despite the fact that for post-tensioned structures the strands are not in direct contact with the concrete, corrosion can still be an issue (Nguyen et al., 2013). This can for example be ascribed to the incomplete filling of the ducts with grout. Voids created as such induce the accessibility of moisture, oxygen and chlorides (from rainwater, seawater, salt-fog or de-icing salts (Zhang, Wang, Zhang, \& Liu, 2017)). Voids in the grout also enable the transport of moisture and chlorides along the tendon and their presence can reduce the bond over parts of the tendon length. Furthermore, chlorides may be latent in the grouting (Schupack, 1994). Expansive grouting has a particularly high level of chlorides, which can induce tendon corrosion. Another possible source initiating the corrosion of the tendons can be the corrosion of the anchorage due to insufficient cover, impermeable materials or a lack of bond. This allows moisture and chlorides to enter the duct. These non-tight anchorages or construction joints (e.g. inadequate sealing of the road surface (Podroužek et al., 2014)) can form the main source of corrosion agents in ungrouted ducts (Page \& Page, 2007). Another source of corrosion can be water that was already present in the ducts of post-tensioning tendons prior to injection, due to which steel might already suffer severe pitting corrosion in the ungrouted and non-prestressed condition. This might lead to a reduction in load-bearing capacity. In current practice, the chloride contents in the water used for grout and concrete mixing should be verified and limited. However, in the past, this was not always the case. Hence, in older existing structures, chlorides can still be present in the concrete or grout. According to Zhang, et al. (2017) strand corrosion in post-tensioned structures can be accelerated by galvanic coupling between the strands and the anchorage body, which might induce anchorage failure. Finally, damage of the duct, improper slices between the duct, and a non-permanent duct can lead to chlorides reaching the tendons as well. Concluding, corrosion in prestressing tendons will mostly be induced by inappropriate construction. If tendons are well installed, corrosion should be very rare (Tu et al., 2019).

Even though corrosion should be very rare if tendons are properly installed, according to Nguyen et al. (2013), considering the practical process of construction, corrosion of tendons happens very often in practice since 
grouting is generally incomplete (Woodward, 2001). The incomplete grouting process leads to voids that contain water and oxygen along the length of the tendon, inducing depassivation of the tendon surface. The corrosion rate will depend on the type of grout and the diffusion of oxygen into the wire surface. The time to corrosion initiation can still be calculated according to equation (1). However, $c$ equals now the distance between the top of the grout and the wire surface, accounting for the void size which is commonly $6 \mathrm{~mm}$ (Nguyen et al., 2013) (see Figure 9). This grout void size is based on experimental experience from an NDT testing company (Fisk \& Armitage, 2019) where a small bleed water void (less than $6 \mathrm{~mm}$ ) was detected in virtually every grout classified as 'good, unvoided' after verification by drilling. The total surface concentration $C_{s}$ will be a combination of the native chloride content of the grout (500 ppm for commercial grout) and the chloride in the air within the void $(0.17 \%)$, or $C_{s}=0.8 \mathrm{~kg} / \mathrm{m}^{3}$ (Nguyen et al., 2013). The diffusion coefficient $D$ will then represent the diffusivity of the grout. Regarding the initial chloride content in the grout, different values are found in literature ranging from $80 \mathrm{ppm}$ for noncommercial grout to $500 \mathrm{ppm}$ in commercial grout (H. Wang, Sagues, \& Powers, 2005). It should also be pointed out that in the general model for reinforcement corrosion, the initial chloride concentration is not taken along in $C_{s}$ but in a parameter $C_{0}$ according to (fib, 2006). In (Virmani \& Ghasemi, 2012) a summary of codes and standards defining maximum allowable chloride limits in grout and prestressed concrete can be found.

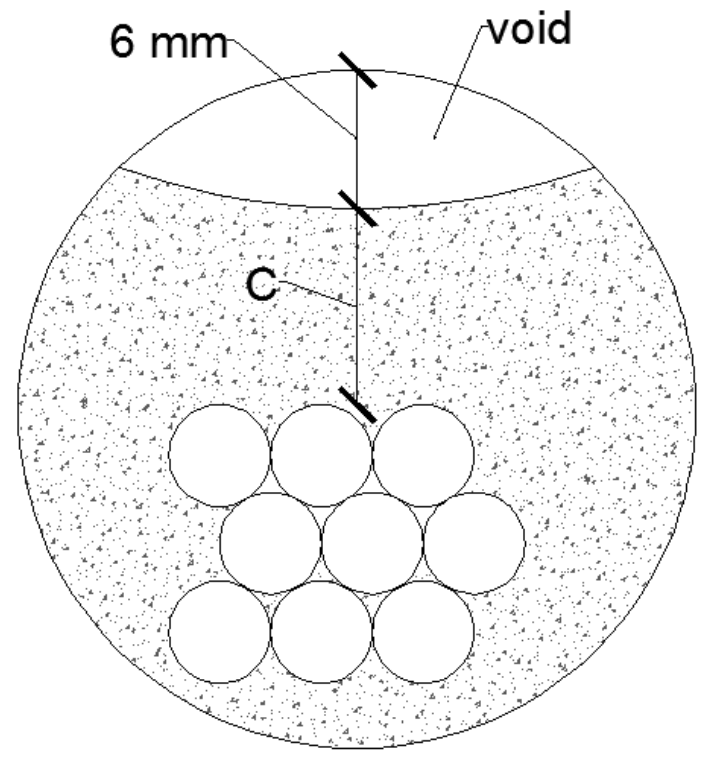

Figure 9 Strands in grouted duct with void

In the case of steel ducts, these ducts can also corrode, which allows corrosive agents to reach the steel surface through the ducts. For example, Guo et al. (2016) consider tendons consisting of stranded wires inside corrugated metal ducts, modelling the time of corrosion initiation of tendons as consisting of three parts:

1) Diffusion of chloride ions from the concrete surface to the metal duct;

2) The time for a pit with a depth equal to the thickness of a duct to form in the metal duct;

3) Diffusion of the chloride ions in the grout.

The distinction between these three phases is also made by Tu et al. (2019), who state that the second phase will have the smallest contribution due to the small duct depth. To overcome this possibility of corrosive agents reaching the steel, strong emphasis is nowadays placed on the quality, integrity and continuity of the duct as a corrosion barrier in itself, replacing steel ducts by plastic equivalents. The better performance of plastic ducts compared to steel ducts is for example illustrated in the experimental research of (Salas, Schokker, West, Breen, \& Kreger, 2008), where macro-cell and column corrosion test results proved that strands and post-tensioning bars in plastic ducts showed no signs of corrosion. In (Salas, Schokker, West, Breen, \& Kreger, 2004), light corrosion of steel in plastic ducts was observed, but with a much better performance compared to the steel ducts. In the latter, severe duct destruction and pitting is observed. If corrosion is present in plastic ducts, it is mostly at locations where the duct is interrupted or where different pieces of the duct are connected. Hence, there is a need for effective splicing and sealing at joints. In (McCool, Ahern, Bree, \& Wood, 2011) different issues due to which plastic ducts can still lead to corrosion are listed: 
- Imperfect sealing;

- $\quad$ Longitudinal splitting of the duct;

- Presence of grout voids;

- Improperly installed duct splices.

They also observed that strands in plastic ducts showed less corrosion than in steel ducts and that corrosion initiated later in plastic ducts. Chlorides do not penetrate trough plastic ducts and the duct itself remains intact. However, breaches in couplers and loosening of epoxy can induce the ingress of chlorides. For new bridges, the advice is hence to use these plastic ducts. Nevertheless, in older bridges steel ducts can still be present since little attention was formerly paid to the possible role of the duct as a barrier to corrosive agents (FHWA, 2013).

The two models for corrosion in post-tensioned ducts described above are based on a completely different origin of the corrosion products and are therefore valid for specific situations. Both initiation period and corrosion rate can differ largely depending on the source of the chlorides. For the first model, assuming a grout cover of $15 \mathrm{~mm}$ between void and tendons, a critical chloride concentration of $0.3 \mathrm{~kg} / \mathrm{m}^{3}$, a surface chloride concentration of 0.8 $\mathrm{kg} / \mathrm{m}^{3}$ and a diffusion coefficient of chlorides in the grout of $10^{-11} \mathrm{~m}^{2} / \mathrm{s}$ (Nguyen et al., 2013), Nguyen et al. (2013) found an initiation period of 15 years by applying a polynomial approximation to equation (1). According to (Nguyen et al., 2013), the corrosion rate in grout equals $6.5 \mu \mathrm{A} / \mathrm{cm}^{2}$ or $0.075 \mathrm{~mm} /$ year. This corrosion rate would correspond to a severe outdoor environment of a tidal zone for RC structures (Lay et al., 2003). When calculating the initiation period applying the models described in (Guo et al., 2016), it would take 15 years before the chlorides would reach the duct and 8 more years before the duct is penetrated. Next, another 15 years could pass before the chlorides reach the tendons within the duct when applying the same assumptions as in (Nguyen et al., 2013). Hence, the second model leads to a much larger initiation period and may as such lead to an underestimation of the actual corrosion degree by disregarding the presence of grout voids. The corrosion rate and initiation period for both models are compared in Table 3. For the model of (Nguyen et al., 2013), where corrosion is governed by the chloride ingress through the grout voids, the corrosion rate corresponds to the corrosion rate in grout and is derived based on the oxygen diffusion coefficient and the resistivity of the grout. The corrosion rate for the model where chloride ingress happens through the concrete and the duct corresponds to the one in concrete, depending on the exposure class of the structure.

Table 3 Comparison between corrosion rate and initiation period for two models to account for corrosion in posttensioned structures

\begin{tabular}{ccc}
\hline & $\begin{array}{c}\text { Chloride ingress through grout } \\
\text { void } \\
\text { (Nguyen et al., 2013) }\end{array}$ & $\begin{array}{c}\text { Chloride ingress through } \\
\text { concrete and pitting of duct } \\
\text { (Guo et al., 2016) }\end{array}$ \\
\hline $\begin{array}{c}\text { Initiation period found/considered } \\
\text { based on the specific } \\
\text { case/publication }\end{array}$ & 15 years & 38 years \\
\hline $\begin{array}{c}\text { Corrosion rate found/considered } \\
\text { based on the specific } \\
\text { case/publication }\end{array}$ & $0.0754 \mathrm{~mm} / \mathrm{year}$ & $\begin{array}{c}0.004-0.07 \mathrm{~mm} / \mathrm{year} \\
\text { depending on exposure class }\end{array}$ \\
\hline
\end{tabular}

Note also that for post-tensioned strands located in external ducts, i.e. outside of the concrete volume, only the first method seems reasonable. Not only is there no first stage of penetration of chlorides through the concrete, but also the choice for steel ducts will often not be made for external tendons since they are more directly exposed to the environment. If a steel duct would be used, there is still a possibility of corrosion of the duct, enabling chlorides from the environment to reach the prestressing steel. Information on the probabilistic models for the corrosion parameters in the model for chloride ingress through grout voids is limited. To close this gap, (Nguyen et al., 2013) suggest to use a Poisson distribution to model the initiation period as a stochastic variable, where the mean value is calculated based on equation (1). Nevertheless, other probability distributions could also be applied. For example, to model the distance between the void and the tendons, models proposed by (JCSS, 2001) for the concrete cover could be applied. The diffusion coefficient of grout and concrete are not that different according to Guo et al., 2016), hence the distributions proposed in (fib, 2006) could be used for this parameter. In a similar way, the distributions from (fib, 2006) for surface chloride concentration and critical chloride concentration could be adopted, using the aforementioned values as mean values for this specific example.

It should be pointed out that, regardless of the origin of the corrosion products, corrosion happens on the single wires of a tendon, where tendon failure will only occur when in all wires in the tendon the critical stress is exceeded. Concerning wire failure, the worst effects are observed for unbonded tendons in post-tensioned elements since brittle failure of these tendons leads to a prestress reduction proportional to the tendons cross-sectional loss (Coronelli et al., 2009). This in contrast to bonded tendons, where a new anchorage on either side of the fracture 
can be developed after failure, due to the bond stresses between steel and concrete/grout. Hence, these failures might have a lower structural impact.

Another important difference between pre-tensioned and post-tensioned structures is the discontinuous character of the concrete cover (Wang et al., 2019). In the case of post-tensioned structures, the concrete cover consists of grout, situated in the duct, which is embedded in the concrete. Hence, strand corrosion will induce first internal grout cracking before it will affect the external concrete. Concerning the influence on concrete cracking, Zhang, Wang, Zhang, Ma, et al. (2017) performed experimental investigations on eight bonded post-tensioned concrete beams with different corrosion levels. These beams were tested up to flexural failure, investigating the effects of corrosion on cracking, stiffness, ultimate strength, failure mode and ductility. They found that the cracking moment almost linearly decreases with increasing strand corrosion. Corrosion of the strands has only a limited influence on the initial stiffness of the post-tensioned beam. After cracking, the influence on the stiffness was found to depend on the strand area loss. Furthermore, strand corrosion accelerates the shift of the neutral axis under selfweight and decreases the depth of the compression zone, leading to a reduced ultimate strength of the beams. Finally, with increasing corrosion loss, the failure mode was observed to change from concrete crushing to strand rupture.

In section 3.4, it was explained how the spatial variation of pitting corrosion could be accounted for in prestressed structures. In post-tensioned structures, the cause of pitting corrosion is different from pre-tensioned structures (i.e. e.g. by the presence of voids). A method to account for this incidental distribution of pits is described by Nguyen, Jeong, Han \& Kong (2013). They subdivide the girder in $n_{M}$ elements. Each of these elements has a length $L_{w}$ and contains $n_{p}$ pits. The number of pits in each element is predicted by a Poisson distribution with mean $n_{p}$ and the number of occurrences equal to the number of elements $n_{M}$. This is based on the assumption that there is only a single pit in one wire in each element. Besides the distribution of pits in an element, the number of pits that can be present in one tendon is also considered random. Nguyen, Jeong, Han \& Kong (2013) use a Poisson distribution to predict the number of pits in one tendon. The mean value of this distribution is equal to one, representing the common case that at least one pit is formed in the tendon. The number of occurrences now equals the number of tendons in an element. As such, the number of pits in each tendon in each element can be calculated. This differs from the approaches by (Darmawan \& Stewart, 2007; Dias-da-Costa et al., 2019), who assume that each strand is exposed to pitting, while the pitting factors for the wires are considered as independent random variables. As such, a different sample for the pitting factor is generated for each wire of each strand in each element. Pitting corrosion caused by penetration of chlorides through the duct will also be characterized by a spatial variability. For the latter, the models summarized in section 3.4 can still be used.

For post-tensioned structures, corrosion of the anchorage head system can also be an issue, as studied in (Li, Luo, $\&$ Liu, 2017). However, this damage phenomenon will not be discussed in this work.

\section{ASSESSMENT OF PRESTRESSED STRUCTURES}

In this section, different methods for the assessment of the strength and remaining prestress force in prestressed structures will be summarized. This ranges from testing to probabilistic predictions accounting for the timedependent degradation.

\subsection{Non-destructive assessment of remaining prestress by dynamic tests}

According to $\mathrm{Vu}$ et al. (2009) there is no possibility to detect damage of the prestress wire through dynamic tests before brittle failure of the wire has occurred. Only once the wire has failed, this will be detectable since there will be a reduction in prestressing force and hence in bending stiffness of the beam. As such, monitoring the response of a prestressed or post-tensioned structure under service loads and subjected to deterioration can reveal the breaking of tendons. However, it should be pointed out that a significant change in the natural frequencies will only be observed if the loss of prestressing produces a sufficiently large reduction in stiffness. That is, if it is large enough to produce cracking up to a certain extent (notice that loss of stiffness in prestressed concrete is not abrupt as in reinforced concrete). If only one strand or only few wires are broken, the latter might not be the case.

Capozucca (2008) investigated the influence of corrosion of prestress reinforcement on the natural frequencies of prestressed structures. In the beams tested by Capozucca (2008), it was found that natural frequencies of a corroded prestressed beam were very similar to those of an undamaged beam. Nevertheless, the results from the static loading tests showed an increased curvature of the section for the corroded beams, as well as a decrease in stiffness and a non-linear moment-curvature diagram. It should be pointed out that the experiments were performed with accelerated corrosion of the reinforcement located in the compressive zone of the concrete. Furthermore, natural frequencies were not determined in loaded conditions. When the beam is subjected to loading, an influence of corrosion on the dynamic response is observed as this causes the cracks to open. This will occur as soon as the 
loading is larger than the cracking loads. In the latter case, reduced natural frequencies are found for beams with a significant corrosion damage.

Also in (Rashetnia, Ghasemzadeh, Hallaji, \& Pour-Ghaz, 2018), the dynamic characteristics of prestressed structures were investigated in order to quantify the prestressing force loss due to corrosion. The prestressing force can be correlated to the natural frequencies according to equation (46) for a simply supported beam subjected to free vibration and an externally applied compressive force, which represents the prestressing force.

$$
\omega_{i}=\frac{i \pi}{L} \sqrt{\frac{1}{m} E I_{0}\left(\frac{i \pi}{L}\right)^{2}-F_{c}}
$$

Here, $\omega_{i}$ is the frequency of mode $i, E I_{0}$ the flexural stiffness of the beam, $L$ its length, $m$ the mass per unit length and $F_{C}$ the axial compressive force. The expression holds for a simply supported prestressed beam with a uniform cross section. The partial differential equation for bending is first solved for the free vibration situation (general homogeneous solution) and then the integration coefficients belonging to the different solutions are determined as a function of the boundary conditions (Clough \& Penzien, 1993). Since equation (46) is only valid for a beam with uniform cross-section, it cannot be used in an inverse analysis to identify cracks or a local loss of stiffness from experimental modal data. This requires more advanced forward models that are able to cover various damage mechanisms. Examples of such damage mechanisms also include the loss in prestressing force following from the deterioration of the bond between strands and concrete, and the microcracking at early stages. Due to these damage mechanisms, a change in the dynamic characteristics of the structure might occur (Rashetnia et al., 2018). Hence, by combining modal data of prestressed concrete beams with indirect estimation approaches, the loss of prestressing force due to corrosion could be quantified according to (Rashetnia et al., 2018).Instead of the model with uniform cross-section considered in the derivation of equation (46), a more advanced forward model can be used, e.g. based on the differential equation describing free vibration of a simply supported prestressed beam, accounting for the axial prestressing force, neglecting shear deformation and rotational bending effects. Rashetnia et al. (2018) validated their method based on tests where the first three natural frequencies for very short simply supported beams subjected to accelerated corrosion were measured.

Another problem considering the assessment of prestressed structures by modal data is the fact that cracks can close again because of the prestress (Unger, Teughels, \& De Roeck, 2006). Because of this closing of the cracks, Unger, Teughels \& De Roeck (2006) showed that damage detection in a prestressed concrete beam is difficult in early damage stages. However, they were able to identify the damage pattern corresponding to the locations of final failure. They also found that, after cracking, the recovery in stiffness due to prestress is not complete. Hence, a reduction of the natural frequencies can be observed. Nevertheless, this difference in natural frequencies (and corresponding mode shapes) is small until yielding of the reinforcement arises and the cracks remain open. With an identification accuracy of $1 \%$ of the measured frequency, damage can be detected at about $50 \%$ of the failure load. Also Anastasopoulos, De Roeck, \& Reynders (2019) state the fact that at high load levels, cracks will remain opened. However, at lower load levels, they will be partially closed by the prestressing force and the neutral axis will be located close to its position in the undamaged state. Nevertheless, in structures such as bridges where the dead weight is significant, the closing of the cracks due to the prestress is less likely to occur. It should also be noted that temperature influences could mask the influences of damage. Hence, modal data should be normalized when it is used for damage evaluation.

Conclusions on the use of dynamic tests for the characterization of corrosion damage and a loss of prestress are summarized in Table 4. Here it can be observed that most authors state that detection of prestress loss by dynamic measurements is only possible if either major prestress losses have occurred or the concrete section is cracked (due to the lower prestress). Whereas conclusions are similar, the scale of the experiments differs from just the wires (Vu et al., 2009), to simply supported beams (Capozucca, 2008; Rashetnia et al., 2018; Saiidi, Douglas, \& Feng, 1994), to real-life girders (Unger et al., 2006). Even though for the latter experiment the ratio of dead load to failure load is smaller than for real life structures, the conclusions might be most representative in order to draw conclusions for real applications because of the size of the tested girder. Hence, only when cracks remain open due to yielding of the reinforcement, a decrease in frequency of a degrading prestressed beam is expected to be observed. 
Table 4 Conclusions on dynamic measurements on prestressed beams

\begin{tabular}{|c|c|c|}
\hline Author & Experiment & Conclusion \\
\hline $\begin{array}{l}\text { (Vu et al., } \\
2009)\end{array}$ & $\begin{array}{l}\text { Modal analysis of } 8 \mathrm{~mm} \text { diameter wires under } \\
\text { tension subjected to accelerated corrosion. }\end{array}$ & $\begin{array}{l}\text { Prestress loss can only be detected after } \\
\text { brittle failure of the wires. }\end{array}$ \\
\hline $\begin{array}{l}\text { (Capozucca, } \\
2008)\end{array}$ & $\begin{array}{l}\text { The load on simply supported beams (undamaged } \\
\text { and damaged) was increased and dynamic tests were } \\
\text { performed at different load levels. The damaged } \\
\text { beams were subjected to electrochemical corrosion. } \\
\text { The beams were composed of a T-section with two } \\
\text { prestressed wires of } 11.93 \mathrm{~mm}^{2} \text { (one in the top flange, } \\
\text { one in the bottom flange). }\end{array}$ & $\begin{array}{l}\text { Limited influence of corrosion if the } \\
\text { beam is unloaded. Only influence if the } \\
\text { applied load is larger than the cracking } \\
\text { load. }\end{array}$ \\
\hline $\begin{array}{l}\text { (Saiidi et al., } \\
\text { 1994) }\end{array}$ & $\begin{array}{l}\text { Field and laboratory tests. Field test: actually post- } \\
\text { tensioned simply supported multi-cell box-girder } \\
\text { bridge. Lab test: beam with } 7 \text {-wire strand in a } 25 \mathrm{~mm} \\
\text { ungrouted duct. } \\
\text { In both cases, the actual prestress was known. }\end{array}$ & $\begin{array}{l}\text { When the prestress decreases } \\
\text { microcracks open and the beam } \\
\text { softens. } \\
\text { Prestress loss is only detectable in the } \\
\text { case of major prestress loss. }\end{array}$ \\
\hline $\begin{array}{l}\text { (Rashetnia et } \\
\text { al., 2018) }\end{array}$ & $\begin{array}{l}\text { Prestressed concrete beams of } 1.5 \mathrm{~m} \text { length } \\
(17.5 \times 17.5 \mathrm{~cm}) \text { and a } 7 \text {-wire } 12.5 \mathrm{~mm} \text { diameter } \\
\text { strand subjected to accelerated corrosion. }\end{array}$ & $\begin{array}{l}\text { Prestressing force drops could be } \\
\text { quantified based on measuring changes } \\
\text { in modal frequencies. }\end{array}$ \\
\hline $\begin{array}{l}\text { (Unger et al., } \\
2006 \text { ) }\end{array}$ & $\begin{array}{l}\text { Post-tensioned beam of } 17.6 \mathrm{~m} \text { length prestress with } \\
\text { an inclined cable. }\end{array}$ & $\begin{array}{l}\text { Damage detection in a prestressed } \\
\text { concrete beam is difficult in early } \\
\text { damage stages due to closing of the } \\
\text { cracks because of the prestress. } \\
\text { However, the damage pattern } \\
\text { corresponding to the locations of final } \\
\text { failure can be identified. }\end{array}$ \\
\hline
\end{tabular}

\subsection{Other non-destructive test methods for estimating the loss of prestress}

Besides dynamic tests, other non-destructive test methods can also be used to get an indication on the remaining level of prestressing. For example in (Webb et al., 2017), distributed strain sensors are used to detect local damage in a prestressed concrete bridge. The sensors used are fibre optic sensors. It should be pointed out that these sensors are very fragile and prone to breaking during installation. In the work of Webb et al. (2017), standard low-cost telecommunication grade fibre-optic cables are used. Unfortunately, they also struggled with the vulnerability of the sensors. Fibres were damaged both during casting of concrete and during installation and transportation of the beams. The sensors were installed before construction of the bridge and performed continuous measurements. Webb et al. (2017) stated that by monitoring the structure by a distributed strain monitoring system, wire breaks in the prestressing tendons could be detected. Individual wire breaks cause very small changes in strain less than one microstrain (Webb, Vardanega, Fidler, \& Middleton, 2014). However, since this is much smaller than the accuracy of strain measurements, individual wire breaks could not be detected. On the other hand, if an entire prestressing strand ruptures, there will be a loss of compression in the concrete and the resulting strains were around 1.85 microstrain in the specific situation studied by Webb et al. (2017). The latter strains are detectable by accurate strain measuring systems (Webb et al., 2017).

Coronelli et al. (2009) loaded beams that are prestressed with a single $8 \mathrm{~mm}$ diameter wire and have cavities in the concrete to simulate the brittle failure of the wire (near the support in one beam, at midspan for another beam) until failure. They monitored the strains and displacements during the loading process. Their results revealed that only tendon breaking at midspan could be revealed by monitoring, while the effects of broken tendons close to the supports could not be detected from the response, since this damage did not lead to any change in response when compared to the reference, undamaged beam. When the wire breaks close to the supports, the remaining portion of wire can provide residual strength, sufficient to resist the load (Coronelli et al., 2009). Nevertheless, also these support zones can be of importance in assessment of the structures, since the breaking of wires in a shear critical location can trigger brittle shear failure when the amount of transverse reinforcement is limited (Coronelli et al., 2009).

Apart from strains, also displacements can be used to assess the remaining level of prestressing, e.g. when measured under proof-loading. In (Sousa, Rozsas, Slobbe \& Courage, 2019) a virtual twin of a bridge was created 
to generate artificial measurement data under proof-loading and investigate the relative information gain of different types of data for different damage scenarios. The information gain is calculated by the explanatory power, representing the reduction in posterior uncertainty compared to the prior uncertainty on the damage parameters. Vertical displacements were measured at the spans of the bridge and were found to have the highest explanatory power for prestress losses, when compared to horizontal bearing displacements, rotations of the deck girders above the piers and concrete deformations on the deck at mid-span and supporting sections. Also Capozucca (2008) found a non-linear load-displacement curve for beams subjected to corrosion, where larger displacements were found in comparison to a non-damaged beam.

\subsection{Reliability assessment}

The assessment of an existing prestressed beam can also be based on structural reliability calculations. For example, Guo et al. (2011) present a framework for the assessment of the time-dependent reliability of existing prestressed concrete box-girder bridges by adopting time-dependent corrosion models (as for example summarized in section 3). Even though this is only based on modelling and not on tests on the real structure, the importance of corrosion on the response can be predicted. Guo et al. (2011) applied truncated Latin hypercube sampling for the evaluation of the failure probability. The types of distributions used for the different variables are summarized in Table 5. For the assumptions on the mean values and standard deviations, the reader is referred to Guo et al. (2011). Failure is defined when the tendon strain exceeds the failure strain.

Table 5 Distributions used for reliability assessment

\begin{tabular}{|c|c|c|c|}
\hline Variable & Guo et al. (2011) & $\begin{array}{c}\text { Distribution } \\
\text { (Darmawan \& Stewart, } \\
\text { 2007) }\end{array}$ & $\begin{array}{c}\text { (Dias-da-Costa et al., } \\
\text { 2019) }\end{array}$ \\
\hline Dead load & Normal & Normal & Normal \\
\hline Live load & $\begin{array}{l}\text { Extreme value } \\
\text { type I }\end{array}$ & Normal & Gumbel \\
\hline $\begin{array}{l}\text { Concrete compressive } \\
\text { strength }\end{array}$ & Normal & Lognormal & N/A \\
\hline Steel yield strength & N/A & Normal & Normal \\
\hline Young's modulus of the steel & N/A & Normal & N/A \\
\hline Concrete cover & Normal & Normal & Lognormal \\
\hline Section height & N/A & Normal & N/A \\
\hline $\begin{array}{l}\text { Surface chloride } \\
\text { concentration }\end{array}$ & Normal & Normal & Normal \\
\hline $\begin{array}{l}\text { Critical chloride } \\
\text { concentration }\end{array}$ & Normal & Normal & Normal \\
\hline $\begin{array}{l}\text { Diffusion coefficient of } \\
\text { concrete }\end{array}$ & Normal & Normal & Normal \\
\hline Corrosion rate & Normal & Normal & Lognormal \\
\hline Pitting factor & Normal & Gumbel & N/A \\
\hline
\end{tabular}

$* \mathrm{~N} / \mathrm{A}=$ Not Applicable

For limit state verification, the estimated transfer length will indicate at which distance from the location of tendon failure the prestressing can still be active (Coronelli et al., 2009). In large spans, the effects of wire breaking may be limited to a small part of the member. Besides the location of tendon failure, also the number of tendons plays an important role in the analysis. When one tendon breaks, this might lead to unloading of the compressed concrete, inducing larger tensile stresses in other nearby tendons. In addition, multiple tendons can fail, each at multiple locations. With wire breaking near midspan, prestressing effects can be completely lost. Brittle shear failures are only triggered when the amount of transverse reinforcement is low.

For the case studied by Darmawan \& Stewart (2007), including the spatial variability of pitting corrosion by dividing a beam in sections with independent pitting corrosion (as mentioned in section 3.4) leads to an increase in failure probability of $10 \%$ when compared to the case where the failure probability is evaluated only considering the section at midspan. When the midspan section analysis would only consider uniform corrosion disregarding the spatial variation, the difference in failure probability mounted up to $20 \%$ in the research of Darmawan \& Stewart (2007). Even when the spatial variation of corrosion was taken into account, the collapse of the girder remained governed by the failure of strands in the mid-section. Furthermore, the effect of spatial variation of pitting corrosion reduces when the number of strands increases due to a reduced variability of steel section (Darmawan $\&$ Stewart, 2007). Hence, the influence of the spatial variability on the probability of failure for ultimate limit states might not always be significant, although it will lead to an important increase in complexity and 
computational time. However, in serviceability limit states, the effect of the spatial variability of pitting corrosion is more pronounced. This could be ascribed to the fact that the loss of strands due to pitting corrosion induces higher tensile stresses in the concrete, leading to concrete cracking. The latter will significantly reduce the stiffness of the girder. Loss of capacity of strands not located in midspan will affect serviceability limit states more than it will affect strength and hence ultimate limit state. Furthermore, dividing a beam in sections where pitting corrosion is assumed to occur independently, results in an increase of the differences in strength between sections as corrosion progresses. This causes a reduction in correlation between the strength of different segments. Hence, the system reliability of the beam modelled as a system consisting of the different elements increases towards the one of uncorrelated elements, where uncorrelated random variables are used (Dias-da-Costa et al., 2019). For an uncorroded girder, the resistance in the different segments could be modelled as statistically independent because failure is then governed by the highest loaded segment. For a simple beam under bending, the highest loaded segment is the midspan segment. The limit states evaluated in (Darmawan \& Stewart, 2007) consider flexural strength and serviceability (peak deflection). The distributions applied are summarized in Table 5. The failure probability is evaluated based on Monte Carlo simulations, as are the distribution of the initiation period and corrosion rate. In (Dias-da-Costa et al., 2019) the ultimate limit state is defined by comparing the maximum traffic load scale the girder can bear with the standard traffic load scale factor. The assumed distribution types are given in Table 5. The reliability index is evaluated based on a combination of FORM analyses and response surface methods.

Two other important notes on the reliability assessment of prestressed structures should be made. A first note is the fact that the corrosion rate is an important variable in the reliability analysis and becomes even more important over time together with the corrosion model error and concrete cover (Dias-da-Costa et al., 2019). Hence, it is important to assume an appropriate distribution for this parameter. The second note is that, in some cases, it may be important to consider the deterioration of the bond (Coronelli et al., 2009), whereas in other cases it may be unimportant or not worth the additional computational effort.

A more simplified assessment method consists of the application of the partial factor method for existing structures according to fib Bulletin 80, as in (Gino, Castaldo, Bertagnoli, Giordano, \& Mancini, 2020) applied for the assessment of an existing prestressed concrete bridge. However, the bridge considered in (Gino et al., 2020) does not present any visible signs of deterioration due to corrosion. As such, investigation is still required whether the applied method is also valid for prestressed/post-tensioned bridges subjected to corrosion. Moreover, Gino et al. (2020) also highlight some deficiencies in the application of the partial factor method to prestressed structures, e.g. the lack of probabilistic models to update partial safety factors for prestressing. Nevertheless, with the addition of some assumptions from the EN 1990 provisions, the partial factor method can be used in the assessment of existing prestressed structures to avoid expensive and unnecessary immediate interventions.

An extensive reliability assessment is not always necessary. Sometimes, a less complex structural assessment with partial factors/safety factors accounting for the uncertainty could be sufficient. For example, from (Bagge et al., 2019) it can be concluded that a prestressed bridge loaded to failure shows highly non-linear structural behaviour with extensive cracking, yielding and large deformations, where the latter give a warning prior to failure. The failure mode was more shear related, with diagonal cracks in the bridge girder and rupture of the shear reinforcement. Also punching of the loading plate through the slab at the top of the girder could occur. Under these circumstances, Bagge et al. (2019) found that simplified structural assessment based on a 2-step procedure of verification of action effects from structural analysis against resistance given by local models gives appreciable conservative estimates of the load-carrying capacity. However, the location of shear failure could not be predicted accurately with these simplified models. When further refining the models accounting for flexural failure and shear related failure, the failure pattern found by the test is represented in the model, but with very conservative estimates of the resistance. Hence, for a more accurate assessment of the resistance, a non-linear FE analysis is recommended by Bagge et al. (2019). In this analysis, the most influential parameters appear to be the concrete compressive and tensile strength, Young's modulus of the concrete, tension stiffening effects, the level of residual prestressing force and the support conditions.

For existing structures, target reliability levels might differ from those of new structures. In (Dias-da-Costa et al., 2019) a target reliability level of 2.5 is used for checking the safety of existing bridges based on (AASHTO, 2008). For existing structures, the use of a minimum target reliability index corresponding to a larger relative cost of safety measures can be justified. For consequence classes 1, 2 and 3 (CEN, 2002) the annual target reliability levels are 3.1, 3.3 and 3.7 respectively, according to (ISO, 2015). Considering human safety requirements, the same levels as for new structures can be used. This is especially relevant for key members for which local failure can result in partial or total collapse of the structure. For existing bridges, reference can also be made to fib bulletin 80 (Caspeele, Steenbergen, \& Sykora, 2016).In fib bulletin 80, the target reliability level for a reference period of 50 years and for existing structures equals the one for new structures according to (CEN, 2002) minus 1.5. Hence, for consequence classes 1, 2 and 3 the target reliabilities are 1.8, 2.3 and 2.8 respectively. When considering human 
safety, a distinction is made between the individual risk and group risk. For the individual risk, considering a reference period of 1 year, the target reliability levels are 3.9, 3.6 and 3.1 for consequence classes 3, 2 and 1 respectively. For group risk, the target reliability depends on the area collapsed. For large collapsing areas, the values of (CEN, 2002) for new structures can also be applied to existing structures. For more detailed formulations, the reader is referred to (Caspeele et al., 2016).

\section{CONCLUSIONS}

In this work, the current state of the art on corrosion of prestressing structures and the structural assessment of these structures is summarized.

Concerning degradation, the most important conclusions are that pitting corrosion due to chlorides is the most important degradation phenomenon for prestressed strands. The high level of prestressing force in these strands accelerates corrosion: the cross-section reduces, leading to higher stresses and higher corrosion rates. This can lead to brittle rupture of the strands. This phenomenon is called stress corrosion cracking. The corrosion degree on the other hand is lower compared to non-prestressed reinforcement bars due to the lower pit depth. The pitting corrosion starts at the outer wires of a 7-wire strand since these are exposed to the chlorides. Not only the steel section decreases, but also properties like ultimate strain and stress will decrease, inducing an altered stress/strain diagram. Corrosion might also influence the bond between the prestressing steel and the concrete, but this influence might be limited due to the local nature of pitting corrosion. When the prestress is in direct contact with the concrete, cracking of this surrounding concrete might occur due to the expansive properties of rust formed at the steel surface. Finally, corrosion of non-prestressed reinforcement bars can influence the stress in the tendons. This might again influence the structural integrity. Hence, degradation in conventional reinforcement bars should also be considered.

Corrosion of post-tensioned tendons can be caused by several phenomena: voids can be present in the grout, chlorides can penetrate in the ducts via the anchorages, ducts might be perforated or corroded (if a metal duct is used), etc. The expansive properties of rust may only lead to cracking of the grout and there is little to no influence on the concrete surrounding the ducts. Even though corrosion is rare if the tendons are properly installed, research reports that there is actually corrosion in almost half of the cases. Furthermore, if the tendons are not bonded, failure of the strands is worse as no stress redistribution can be formed in this case.

An experimental assessment of the remaining level of prestress is difficult. The static and/or dynamic response to loads can be measured, where deterioration of stiffness and capacity can reveal tendon breaking, in particular at midspan location. On the other hand, the effect of tendon breaking at the supports might not be observed from these responses. The dynamic response of a prestressed structure might change due to microcracking and the deterioration of the bond between steel and concrete. However, this generally leads to small changes in the natural frequencies. If a major prestress loss occurs, the dynamic characteristics will show significant changes corresponding to this prestress loss. Hence, by periodic monitoring, these drastic changes could be detected.

Based on this review, it becomes clear that some important points for future research remain:

- Lots of (experimental) research is available on the influence of pitting corrosion on the remaining steel section of prestressed or post-tensioned strands and/or tendons. However, a consensus has not been reached yet as on how this pitting corrosion for prestressed strands or tendons should be modelled.

- Different models can be found in literature for the influence of corrosion on the steel properties of prestressed elements. Nevertheless, these models may lead to different results. Hence, a consensus is needed, as on which reductions are important to account for, which are less relevant, and how to model the effect of corrosion.

- Some more simple models for the influence of corrosion on the concrete (i.e. cracking and a resulting stiffness loss) are required.

- There is until now no clear guideline on how to properly account for the spatial variation of corrosion.

- More research is required on the modelling of the initiation and propagation period for post-tensioned structures, considering the different possible origins of the chlorides (i.e. by the presence of grout voids or by pitting corrosion through the duct).

- More research is required on how to (experimentally) assess the presence of corrosion and the corrosion degree.

- Important challenges lie in the non-destructive assessment of the remaining level of prestress. Inspections including different types of measurements and/or data might be performed on the structure. However, it is not clear yet how the resulting data can be used to improve the estimate of the prestress losses and/or the remaining prestress. Bayesian methods might be used for this purpose, transforming a vague prior 
distribution of the remaining prestress to a smaller posterior distribution based on the available data. This last approach is applied in (Botte, Vereecken, Taerwe, \& Caspeele, 2021), where the posterior distribution of the remaining prestress of a prestressed roof girder is determined based on experimental data.

\section{ACKNOWLEDGEMENTS}

This research has been made possible through funding from the Research Foundation Flanders (FWO), which is gratefully acknowledged.

\section{REFERENCES}

AASHTO. (2008). Manual for bridge evaluation. American Association of State Transportation and Communication.

Anastasopoulos, D., De Roeck, G., \& Reynders, E. P. B. (2019). Influence of damage versus temperature on modal strains and neutral axis positions of beam-like structures. Mechanical Systems and Signal Processing, 134, 106311. https://doi.org/10.1016/j.ymssp.2019.106311

Bagge, N., Plos, M., \& Popescu, C. (2019). A multi-level strategy for successively improved structural analysis of existing concrete bridges: examination using a prestressed concrete bridge tested to failure. Structure and Infrastructure Engineering, 15(1), 27-53. https://doi.org/10.1080/15732479.2018.1476562

Bazant, Z. P., \& Gambarova, P. G. (1980). Rough crack models in reinforced concrete. J. Struct. Eng., ASCE 106(4), 819-842.

Belletti, B., Corres Peiretti, H., Andrade, C., Ghiretti, M., Franceschini, L., \& Vecchi, F. (2020). Evaluation of the Residual Life of Corroded Prestressed Concrete Beams. Proceedings of the Fib CACRCS DAYS 2020. Capacity Assessment of Corroded Reinforced Concrete Structures, 1-4 December 2020, 429-437.

Belletti, B., Scolari, M., \& Vecchi, F. (2017). PARC_CL 2.0 crack model for NLFEA of reinforced concrete columns subjected to cyclic loadings. Computer and Structures, 191, 165-179.

Belletti, B., Vecchi, F., Bandini, C., Andrade, C., \& Montero, J. S. (2020). Numerical evaluation of the corrosion effects in prestressed concrete beams without shear reinforcement. Structural Concrete, (December 2019), 1-16. https://doi.org/10.1002/suco.201900283

Bolzoni, F., \& Gastaldi, M. (2020). Experimental evaluatin of rebars corrosion in concrete. Proceedings of the Fib CACRCS DAYS 2020 - Capacity Assessment of Corroded Reinforced Concrete Structures, 1-4 December 2020, 31-38.

Botte, W., Vereecken, E., Taerwe, L., \& Caspeele, R. (2021). Assessment of Posttensioned Concrete Beams from the 1940's: Large-Scale Load Testing, Numerical Analysis and Bayesian Assessment of Prestressing Losses. Structural Concrete.

Cairns, J., Plizzari, G. A., Du, Y., Law, D. W., \& Franzoni, C. (2005). Mechanical Properties of CorrosionDamaged Reinforcement SIMULATED PITTING DAMAGE. Test, 102-M29(102), 256-264.

Capozucca, R. (2008). Detection of damage due to corrosion in prestressed RC beams by static and dynamic tests. Construction and Building Materials, 22(5), 738-746.

https://doi.org/10.1016/j.conbuildmat.2007.01.025

Caspeele, R., Steenbergen, R., \& Sykora, M. (2016). fib Bulletin 80: Partial factor methods for existing concrete structures. Retrieved from http://www.prescqipp.info/opioid-patches/send/120-opioid-patches/1467bulletin-80-opioid-patches

CEN. (2002). EN 1990: Basis of structural design. Brussels.

CEN. (2005). EN 1992-1-1: Eurocode 2: Design of concrete structures - Part 1-1: General rules and rules for buildings.

Clough, R. W., \& Penzien, J. (1993). Dynamics of structures (2nd editio). McGraw-Hill.

Coronelli, D., Castel, A., Vu, N. A., \& François, R. (2009). Corroded post-tensioned beams with bonded tendons and wire failure. Engineering Structures, 31(8), 1687-1697. 
https://doi.org/10.1016/j.engstruct.2009.02.043

Dai, L., Wang, L., Zhang, J., \& Zhang, X. (2015). A global model for corrosion-induced cracking in prestressed concrete structures. Engineering Failure Analysis, 62, 263-275. https://doi.org/10.1016/j.engfailanal.2016.01.013

Darmawan, M. S. (2009). Pitting Corrosion Model for Partial Prestressed Concrete (Pc) Structures in a Chloride Environment. IPTEK The Journal for Technology and Science, 20(3). https://doi.org/10.12962/j20882033.v20i3.109

Darmawan, M. S., \& Stewart, M. G. (2007). Spatial time-dependent reliability analysis of corroding pretensioned prestressed concrete bridge girders. Structural Safety, 29(1), 16-31. https://doi.org/10.1016/j.strusafe.2005.11.002

DIANA FEA BV. (2019). DIANA User’s Manual - Release 10.3. Retrieved from https://dianafea.com/manuals/d103/Diana.html

Dias-da-Costa, D., Neves, L. A. C., Gomes, S., Hadigheh, S. A., \& Fernandes, P. (2019). Time-dependent reliability analyses of prestressed concrete girders strengthened with CFRP laminates. Engineering Structures, 196(June). https://doi.org/10.1016/j.engstruct.2019.109297

Du, Y. G., Clark, L. A., \& Chan, A. H. C. (2005). Residual capacity of corroded reinforcing bars. Magazine of Concrete Research, 57(3), 135-147. https://doi.org/10.1680/macr.2005.57.3.135

Duracrete. (2000). DuraCrete - Probabilistic Performance based Durability Design of Concrete Structures. Report No BE9521347.

FHWA. (2013). Post-Tensioning Tendon Installation and Grouting Manual. (May), 184.

fib. (2006). fib Bulletin 34: Model code for service life design. Lausanne.

Fisk, P., \& Armitage, B. (2019). Nondestructive Testing for Voided and Soft Grout in Internal Post-Tensioning Ducts. Post Tensioning Institute Journal, 15(July), 31-35.

Gambarova, P. G., \& Karakoç, C. (1983). A new approach tot the analysis of the confinement role in regularly cracking concrete elements. Trans. 7th Struct. Mech. In Reactor Tech., H, 251-261.

Gino, D., Castaldo, P., Bertagnoli, G., Giordano, L., \& Mancini, G. (2020). Partial factor methods for existing structures according to fib Bulletin 80: Assessment of an existing prestressed concrete bridge. Structural Concrete, 21(1), 15-31. https://doi.org/10.1002/suco.201900231

González, J. A., Andrade, C., Alonso, C., \& Feliu, S. (1995). Comparison of rates of general corrosion and maximum pitting penetration on concrete embedded steel reinforcement. Cement and Concrete Research, 25(2), 257-264.

Guo, T., Chen, Z., Liu, T., \& Han, D. (2016). Time-dependent reliability of strengthened PSC box-girder bridge using phased and incremental static analyses. Engineering Structures, 117, 358-371. https://doi.org/10.1016/j.engstruct.2016.03.011

Guo, T., Frangopol, D. M., Han, D., \& Chen, Y. (2011). Probabilistic assessment of deteriorating prestressed concrete Box-Girder bridges under increased vehicle loads and aggressive environment. Journal of Performance of Constructed Facilities, 25(6), 564-576. https://doi.org/10.1061/(ASCE)CF.19435509.0000174

Guo, T., Sause, R., Frangopol, D. M., \& Li, A. (2011). Time-dependent reliability of PSC box-girder bridge considering creep, shrinkage, and corrosion. Journal of Bridge Engineering, 16(1), 29-43. https://doi.org/10.1061/(ASCE)BE.1943-5592.0000135

ISO. (2015). ISO 2394:2015: General principles on reliability for structures (4th ed). (I. O. for Standardization, Ed.). Geneva, Switzerland.

JCSS. (2001). Probabilistic Model Code. Retrieved from http://www.jcss.ethz.ch

Jeon, C. H., Lee, J. Bin, Lon, S., \& Shim, C. S. (2019). Equivalent material model of corroded prestressing steel strand. Journal of Materials Research and Technology, 8(2), 2450-2460. https://doi.org/10.1016/j.jmrt.2019.02.010 
Kashani, M. M., Crewe, A. J., \& Alexander, N. A. (2013). Nonlinear stress-strain behaviour of corrosiondamaged reinforcing bars including inelastic buckling. Engineering Structures, 48, 417-429. https://doi.org/10.1016/j.engstruct.2012.09.034

Lay, S., Schieß1, P., \& Cairns, J. (2003). Lifecon Deliverable D3.2.

Li, F., Luo, X., \& Liu, Z. (2017). Corrosion of anchorage head system of post-tensioned prestressed concrete structures under chloride environment. Structural Concrete, 18(6), 902-913. https://doi.org/10.1002/suco.201600140

Li, F., Yuan, Y., \& Li, C. Q. (2011). Corrosion propagation of prestressing steel strands in concrete subject to chloride attack. Construction and Building Materials, 25(10), 3878-3885. https://doi.org/10.1016/j.conbuildmat.2011.04.011

Li, N., Maekawa, K., \& Okamura, H. (1989). Contact density model for stress transfer across cracks in concrete. University of Tokyo XL.

LNEC E-464. (2005). Concrete prescriptive methodology to estimate concrete properties to achieve the design service life under environment conditions XC or XS. National Laboratory of Civil Engineering (LNEC), Lisbon, Portugal;

Lu, Z. H., Li, F., \& Zhao, Y. G. (2016). An investigation of degradation of mechanical behaviour of prestressing strands subjected to chloride attacking. International Conference on Durability of Concrete Structures, ICDCS 2016, 57-65. https://doi.org/10.5703/1288284316111

Lv, Q., \& Zhu, R. (2016). Model for forecasting the time of corrosion-induced reinforced concrete cracking. In J. L. T. Dilum Fernando, Jin-Guang Teng (Ed.), Proceedings of the Second International Conference on Performance-based and Life-cycle Structural Engineering (PLSE 2015) (pp. 902-910). https://doi.org/10.14264/uql.2016.511

Malumbela, G., Moyo, P., \& Alexander, M. (2012). A step towards standardising accelerated corrosion tests on laboratory reinforced concrete specimens. Journal of the South African Institution of Civil Engineering, 54(2), 78-85.

McCool, G. E., Ahern, M. E., Bree, J. E., \& Wood, S. L. (2011). Evaluation of Corrosion Resistance of Improved Post-tensioning Materials after Long-term Exposure Testing.

Monteiro, I., Branco, F. A., Brito, J. De, \& Neves, R. (2012). Statistical analysis of the carbonation coefficient in open air concrete structures. Construction and Building Materials, 29, 263-269. https://doi.org/10.1016/j.conbuildmat.2011.10.028

Moravcik, M., Bujnakova, P., \& Bahleda, F. (2020). Failure and damage of a first-generation precast prestressed bridge in Slovakia. Structural Concrete, (December 2019), 1-10. https://doi.org/10.1002/suco.201900526

Naito, C., Sause, R., Hodgson, I., Pessiki, S., \& Desai, C. (2006). Forensic Evaluation of Prestressed Box Beams from the Lake View Drive over I- Forensic Evaluation of Prestressed Box Beams from the Lake View Drive over I-70 Bridge.

Nguyen, V., Jeong, M. C., Han, T. S., \& Kong, J. S. (2013). Reliability-based optimisation design of posttensioned concrete box girder bridges considering pitting corrosion attack. Structure and Infrastructure Engineering, (May 2013), 37-41.

Osborn, G. P., Barr, P. J., Petty, D. A., Halling, M. W., \& Brackus, T. R. (2012). Residual prestress forces and shear capacity of salvaged prestressed concrete bridge girders. Journal of Bridge Engineering, 17(2), 302309. https://doi.org/10.1061/(ASCE)BE.1943-5592.0000212

Page, C. L., \& Page, M. M. (2007). Durability of concrete and cement composites. Cambridge: Woodhead Publishing Limited.

Papé, T. M., \& Melchers, R. E. (2011). The effects of corrosion on 45-year-old pre-stressed concrete bridge beams. Structure and Infrastructure Engineering, 7(1), 101-108. https://doi.org/10.1080/15732471003588411

Podroužek, J., Strauss, A., \& Bergmeister, K. (2014). Robustness-based performance assessment of a prestressed concrete bridge. Structural Concrete, 15(2), 248-257. https://doi.org/10.1002/suco.201300002 
Rashetnia, R., Ghasemzadeh, F., Hallaji, M., \& Pour-Ghaz, M. (2018). Quantifying prestressing force loss due to corrosion from dynamic structural response. Journal of Sound and Vibration, 433, 129-137. https://doi.org/10.1016/j.jsv.2018.07.012

Saiidi, M., Douglas, B., \& Feng, S. (1994). Prestressinf force effect on vibration frequency of concrete bridges. 120(7), 2233-2241.

Salas, R M, Schokker, A. J., West, J. S., Breen, J. E., \& Kreger, M. E. (2004). Conclusions, Recommendations and Design Guidelines for Corrosion. 7(22), 85 p. Retrieved from http://www.utexas.edu/research/ctr/pdf_reports/0_1405_9.pdf

Salas, Rubén M., Schokker, A. J., West, J. S., Breen, J. E., \& Kreger, M. E. (2008). Corrosion risk of bonded, post-tensioned concrete elements. PCI Journal, 53(1), 89-107. https://doi.org/10.15554/pcij.01012008.89.108

Schupack, M. (1994). Durability study of a 35-year-old post-tensioned bridge. Journal of Concrete International, 16, 54-58.

Sousa, H., Rozsas, A., Slobbe, A., \& Courage, W. (2019). A novel pro-active approach towards SHM-based bridge management supported by FE analysis and Bayesian methods. Structure and Infrastructure Engineering, O(0), 1-14. https://doi.org/10.1080/15732479.2019.1649287

Stewart, M. G. (2009). Mechanical behaviour of pitting corrosion of flexural and shear reinforcement and its effect on structural reliability of corroding RC beams. Structural Safety, 31(1), 19-30. https://doi.org/10.1016/j.strusafe.2007.12.001

Stewart, M. G., \& Al-Harthy, A. (2008). Pitting corrosion and structural reliability of corroding RC structures: Experimental data and probabilistic analysis. Reliability Engineering and System Safety, 93(3), 373-382. https://doi.org/10.1016/j.ress.2006.12.013

Stewart, M. G., \& Rosowsky, D. V. (1998). Time-dependent reliability of deteriorating reinforced concrete bridge decks. Structural Safety, 20(1), 91-109. https://doi.org/10.1016/S0167-4730(97)00021-0

Tu, B., Dong, Y., \& Fang, Z. (2019). Time-Dependent Reliability and Redundancy of Corroded Prestressed Concrete Bridges at Material, Component, and System Levels. Journal of Bridge Engineering, 24(9). https://doi.org/10.1061/(ASCE)BE.1943-5592.0001461

Tuutti, K. (1982). Corrosion of steel in concrete. Stockholm: Swedish Cement and Concrete Research Institute.

Unger, J. F., Teughels, A., \& De Roeck, G. (2006). System Identification and Damage Detection of a Prestressed Concrete Beam. Journal of Structural Engineering, 132(11), 1691-1698. https://doi.org/10.1061/_ASCE_0733-9445_(2006)_132:11(_1691_)

Val, D. V., \& Melchers, R. E. (1997). Reliability of Deteriorating RC Slab Bridges. Journal of Structural Engineering, 123(1993), 1638-1644.

Vecchi, F., Belletti, B., \& Imperia, L. (2020). Ultimate chord rotation model of corroded reinforced concrete columns subjected to cyclic loading. Proceedings of the Fib CACRCS DAYS 2020 - Capacity Assessment of Corroded Reinforced Concrete Structures, 1-4 December 2020, 385-393.

Virmani, P. Y., \& Ghasemi, H. (2012). Literature Review of Chloride Threshold Values for Grouted PostTensioned Tendons. FHWA Publication No.: FHWA-HRT-12-067. Retrieved from http://www.fhwa.dot.gov/research/

Vu, N. A., Castel, A., \& François, R. (2009). Effect of stress corrosion cracking on stress-strain response of steel wires used in prestressed concrete beams. Corrosion Science, 51(6), 1453-1459. https://doi.org/10.1016/j.corsci.2009.03.033

Walraven, J. . (1980). Aggregate Interlock: a Theoretical and Experimental Analysis. Delft University of Technology.

Walraven, J. C., \& Reinhardt, H. W. (1981). Theory and experiments on the mechanical behaviour of cracks in plain and reindorced concrete subjected to shear loading. Heron 26, 1(a), 5-68.

Walraven, J. C., Vos, E., \& Reinhardt, H. W. (1979). Experiments on shear transfer in cracks in concrete. Part I: Description of results. Delft University of Technology Report, (5-79-3), 1-98. Retrieved from 
https://repository.tudelft.nl/islandora/object/uuid\%3A97fbae46-94e6-4cf5-901c-4ba76f28e682

Wang, H., Sagues, A. A., \& Powers, R. (2005). Corrosion of the Strand-Anchorage System in Post-Tensioned Grouted Assemblies. Corrosion 2005, (05295), 1-27.

Wang, L., Dai, L., Bian, H., Ma, Y., \& Zhang, J. (2019). Concrete cracking prediction under combined prestress and strand corrosion. Structure and Infrastructure Engineering, 15(3), 285-295. https://doi.org/10.1080/15732479.2018.1550519

Wang, L., Yi, J., Zhang, J., Jiang, Y., \& Zhang, X. (2017). Effect of corrosion-induced crack on the bond between strand and concrete. Construction and Building Materials, 153, 598-606. https://doi.org/10.1016/j.conbuildmat.2017.07.113

Wang, L., Zhang, X., Zhang, J., Dai, L., \& Liu, Y. (2017). Failure analysis of corroded PC beams under flexural load considering bond degradation. Engineering Failure Analysis, 73, 11-24. https://doi.org/10.1016/j.engfailanal.2016.12.004

Webb, G. T., Vardanega, P. J., Fidler, P. R. A., \& Middleton, C. R. (2014). Analysis of structural health monitoring data from hammersmith flyover. Journal of Bridge Engineering, 19(6), 1-11. https://doi.org/10.1061/(ASCE)BE.1943-5592.0000587

Webb, G. T., Vardanega, P. J., Hoult, N. A., Fidler, P. R. A., Bennett, P. J., \& Middleton, C. R. (2017). Analysis of fiber-optic strain-monitoring data from a prestressed concrete bridge. Journal of Bridge Engineering, 22(5), 1-14. https://doi.org/10.1061/(ASCE)BE.1943-5592.0000996

Woodward, R. (2001). Durability of post-tensioned tendons on road bridges in the UK. In Federation internationale du Béton (Ed.), Proceedings of workshop on durability of post-tensioning tendons, Fédération Internationale du Béton (FIB) (pp. 78-88). Lausanne.

Zhang, X., Wang, L., Zhang, J., \& Liu, Y. (2017). Corrosion-induced flexural behavior degradation of locally ungrouted post-tensioned concrete beams. Construction and Building Materials, 134, 7-17. https://doi.org/10.1016/j.conbuildmat.2016.12.140

Zhang, X., Wang, L., Zhang, J., Ma, Y., \& Liu, Y. (2017). Flexural behavior of bonded post-tensioned concrete beams under strand corrosion. Nuclear Engineering and Design, 313, 414-424. https://doi.org/10.1016/j.nucengdes.2017.01.004 